\title{
Gene Editing Preserves Visual Functions in a Mouse Model of Retinal Degeneration
}

\author{
Paola Vagni', Laura E. Perlini', Naïg A. L. Chenais' ${ }^{1}$, Tommaso Marchetti', \\ Martina Parrini2 ${ }^{2}$ Andrea Contestabile ${ }^{2 t}$, Laura Cancedda ${ }^{2,3+}$ and Diego Ghezzi ${ }^{2 * t}$
}

${ }^{1}$ Medtronic Chair in Neuroengineering, Center for Neuroprosthetics and Institute of Bioengineering, School of Engineering, École Polytechnique Fédérale de Lausanne, Lausanne, Switzerland, ${ }^{2}$ Laboratory of Local Micro-environment and Brain Development, Department of Neuroscience and Brain Technologies, Istituto Italiano di Tecnologia, Genoa, Italy, ${ }^{3}$ Dulbecco Telethon Institute, Roma, Italy

\section{OPEN ACCESS}

Edited by:

Stylianos Michalakis,

Ludwig Maximilian University

of Munich, Germany

Reviewed by:

Nicolás Cuenca,

University of Alicante, Spain Knut Stieger,

University of Giessen, Germany

${ }^{*}$ Correspondence:

Diego Ghezzi

diego.ghezzi@epfl.ch

${ }^{\dagger}$ These authors have contributed equally to this work

Specialty section:

This article was submitted to

Neurodegeneration,

a section of the journal

Frontiers in Neuroscience

Received: 02 May 2019

Accepted: 21 August 2019

Published: 10 September 2019

Citation:

Vagni P, Perlini LE, Chenais NAL, Marchetti T, Parrini M, Contestabile A,

Cancedda L and Ghezzi D (2019)

Gene Editing Preserves Visual

Functions in a Mouse Model of Retinal

Degeneration.

Front. Neurosci. 13:945.

doi: 10.3389/fnins.2019.00945
Inherited retinal dystrophies (IRDs) are a large and heterogeneous group of degenerative diseases caused by mutations in various genes. Given the favorable anatomical and immunological characteristics of the eye, gene therapy holds great potential for their treatment. Our goal is to validate the preservation of visual functions by viral-free homology directed repair (HDR) in an autosomal recessive loss of function mutation. We used a tailored gene editing system based on clustered regularly interspaced short palindromic repeats (CRISPR)/CRISPR-associated protein 9 (Cas9) to prevent retinal photoreceptor death in the retinal degeneration 10 (Rd10) mouse model of retinitis pigmentosa. We tested the gene editing tool in vitro and then used in vivo subretinal electroporation to deliver it to one of the retinas of mouse pups at different stages of photoreceptor differentiation. Three months after gene editing, the treated eye exhibited a higher visual acuity compared to the untreated eye. Moreover, we observed preservation of light-evoked responses both in explanted retinas and in the visual cortex of treated animals. Our study validates a CRISPR/Cas9-based therapy as a valuable new approach for the treatment of retinitis pigmentosa caused by autosomal recessive loss-of-function point mutations.

Keywords: vision, gene editing, retinal degeneration, in vivo electroporation, photoreceptors

\section{INTRODUCTION}

Retinitis pigmentosa is a group of IRDs that cause the progressive death of retinal photoreceptors and eventually blindness (Ferrari et al., 2011). The treatment of retinitis pigmentosa is still a major challenge because of the early death of rod photoreceptors and the late onset of the symptoms. Daily vision in humans mainly depends on cone photoreceptors, which in retinitis pigmentosa degenerate only at a late stage: likely because cones metabolically depend on rods, which provide them nutrients (Narayan et al., 2016). Therefore, acting on the principal cause of degeneration, namely at the level of rod photoreceptors, would be an effective therapeutic approach to preserve vision in retinitis pigmentosa. Notably, rod-rich photoreceptor transplantations can halt cone loss in degenerating retinas (Mohand-Said et al., 2000).

Mutations in the $\beta$-domain of the phosphodiesterase 6 (PDE6B) gene, which hydrolyses cyclic guanosine monophosphate (cGMP) and initiates phototransduction, are among the most commonly identified causes of autosomal recessive retinitis pigmentosa (Danciger et al., 1995; 
McLaughlin et al., 1995). Missense mutations in PDE6B lead to photoreceptor death, triggered by the toxic accumulation of cGMP (Ulshafer et al., 1980), and result in a progressive loss of visual function, starting from the peripheral retina and progressing toward the center. The discovery of naturally occurring mouse models carrying mutations on the Pde6b gene (Chang et al., 2002, 2007) has provided a better understanding of the mechanisms underlying retinal degeneration and has prompted the development of new therapies. The Rd10 mouse carries an autosomal recessive loss-of-function missense point mutation in the Pde6b gene (exon 13; C1678T R560C), leading to the progressive degeneration of photoreceptor cells. Rd10 mice are particularly useful as an animal model for autosomal recessive retinitis pigmentosa since the slow degeneration of photoreceptor cells recapitulates the time course of the disease in patients.

The first genetic approaches to vision restoration in the Rd10 mouse was based on virus-mediated supplementation of the Pde6b gene (Bennett et al., 1996; Jomary et al., 1997; Pang et al., 2008, 2012). Similarly, viral gene transfer therapies have led to promising results for Leber Congenital Amaurosis 2 and some other retinal diseases, as demonstrated by the several ongoing clinical trials (Auricchio et al., 2017). Recently, gene editing tools based on CRISPR/Cas9 have completely revolutionized gene therapy (Heidenreich and Zhang, 2016). The Cas9 nuclease utilizes a guide RNA (gRNA) to induce DNA double-strand breaks (DSBs) at a precise location in the target genomic site. CRISPR/Cas9 system is easily tuneable, versatile, and enables the precise correction of genetic defects directly on the patient genome. The CRISPR/Cas9 system can either be used to disrupt the target gene by non-homologous end-joining (NHEJ) of DSBs or to edit the target gene by HDR in the presence of a DNA donor sequence (repair template). Importantly, the expression of the CRISPR/Cas9 system is only needed for the relatively short period necessary to correct the genetic mutation (a few days, rather than continuously as in the case of gene supplementation therapies) (Ran et al., 2013).

In this study, we designed a CRISPR/Cas9 gene editing system that can repair the genetic mutation in the $\mathrm{Rd} 10$ mouse model taking advantage of the increased activity of the HDR mechanism in dividing progenitor cells (SalehGohari and Helleday, 2004). We tested the efficiency of the designed approach first in vitro and then in vivo. To demonstrate the phenotype reversal, we performed behavioral and electrophysiological analysis on treated and control mice. Overall, the treated mice retained $50 \%$ of the normal visual acuity even 3 months after the treatment.

\section{MATERIALS AND METHODS}

\section{Construct Design and Cloning}

The online CRISPR Design Tool $^{1}$ was used to design the gRNAs targeting the mouse gene $P d e 6 b$ at the level of the

${ }^{1}$ http://tools.genome-engineering.org mutation c.1678C $>$ T. The sequence of the gene was used as input, and the first three best scoring gRNAs were selected. gRNA \#1 and gRNA \#3 flanked the mutation c.1678C > T (mapping respectively, upstream and downstream the mutation), while gRNA \#2 and its Rd10-mutated counterpart gRNA \#4 mapped on the mutation. The gRNA sequences (\#n) are the following: gRNA \#1, gtggtaggtgattcttcgat; gRNA \#2, tgaagccgtggcgccagttg; gRNA \#3, tctgggctacattgaagccg; gRNA $\# 4$, tgaagccgtggcaccagttg. The gRNA \#2 and \#4 differ only for one base (in bold). The oligonucleotides to generate the gRNAs (Integrated DNA Technologies) were annealed in vitro and cloned in the BbsI sites of the pSpCas9(BB)-2A-GFP plasmid (\#48138, Addgene). The original $\mathrm{CBh}$ promoter in pSpCas9(BB)-2A-GFP plasmid was then replaced with the CAGGs promoter from pCAGGs-mCherry (\#41583, Addgene). The obtained pCAGGs-Cas9(BB)-2A-GFP-gRNA plasmid was subsequently used for the in vitro experiments. To design the single-stranded oligodeoxynucleotide ( $s$ ODN) to use as repair templates, we took advantage of a BanI restriction site in the target sequence to develop a screening assay that allowed us to distinguish between the edited and the nonedited sequences. The BanI restriction site (GGYRCC, where $\mathrm{Y}=\mathrm{C}$ or $\mathrm{T}$ and $\mathrm{R}=\mathrm{A}$ or $\mathrm{G}$ ) maps just downstream to the c.1678C $>\mathrm{T}$ mutation and is present both in the wild type (WT) (GGCGCC) and the Rd10 (GGTGCC) Pde6b sequence. We designed individual ssODN repair templates for each gRNA (Table 1) in order to introduce a silent mutation in the corresponding gRNA PAM sequence (NGG) to avoid Cas9 mediated re-processing of the edited DNA strand. Moreover, the repair ssODNs (Integrated DNA Technologies, Ultramer ${ }^{\text {TM }}$ DNA oligo) were designed to restore the codon coding for the Arginine (mutated into a Cystein in the Rd10 mice, R560C) and concomitantly destroy the BanI restriction site (TGC to AGA). Since the gRNA \#2 and \#4 differ only by one base, they share the same ssODN.

TABLE 1 | sSODNs coupled with each gRNA.

\begin{tabular}{|c|c|c|}
\hline ssODN & gRNA & DNA sequence \\
\hline 1 & 1 & $\begin{array}{l}\text { Ccctctgattcatctagcccatccaatttacatacgtaccatgagt } \\
\text { agggtaaacatggtctgggctacattgaagccgtgTCTccagtt } \\
\text { gtggtaggtgattcttcgatatgctttgctgacagagaatagaa } \\
\text { agcgcaccaagacctggggagcagagtacatgtgggttctgag } \\
\text { atccacatatgagcctacacagc }\end{array}$ \\
\hline 2 & 2 and 4 & $\begin{array}{l}\text { gctgtggtccttgccccagccctctgattcatctagcccatccaatt } \\
\text { tacatacgtaccatgagtagggtaaacatggtctgggctacattga } \\
\text { agccgtgTCTccagttgtgataggtgattcttcgataggctttgc } \\
\text { tgacagagaatagaaagcgcaccaagacctggggagcagagt } \\
\text { acatgtgggttctgagatcc }\end{array}$ \\
\hline 3 & 3 & $\begin{array}{l}\text { Agaagatagttagctgtggtccttgccccagccctctgattcatct } \\
\text { agcccatccaatttacatacgtaccatgagtagggtaaacatggt } \\
\text { ctgggctacattgaagccgtgICTccagttgtggtaggtgatt } \\
\text { cttcgataggctttgctgacaggaatagaaagcgcaccaagacct } \\
\text { ggggagcagagtacatgtgg }\end{array}$ \\
\hline
\end{tabular}

The sequences in bold represent the gRNAs and the ones in bold capital letters represent the edited bases that restore the Arginine and delete the Banl restriction site. The bases underlined are those mutated in the PAM sequence. The SSODNs are antisense to the Pde6b sequence. 


\section{Neuro 2A Cell Culture and Transfection}

Mouse Neuro 2A (N2A) cells (ATCC ${ }^{\circledR}$ CCL-131 ${ }^{\mathrm{TM}}$ ) were cultured in Dulbecco's minimum essential medium (DMEM, Life Technologies) supplemented with $10 \%$ fetal calf serum (Life Technologies), $1 \%$ L-glutamine, $100 \mathrm{U} \mathrm{ml}^{-1}$ penicillin, and $100 \mathrm{mg} \mathrm{ml}^{-1}$ streptomycin (Biowhittaker-Lonza). Cells were maintained at $37^{\circ} \mathrm{C}$ in a $5 \% \mathrm{CO}_{2}$ humidified atmosphere. The cells were transfected with Fugene 6 (Roche). The day before transfection $5 \times 10^{5} \mathrm{~N} 2 \mathrm{~A}$ cells were plated on $6 \mathrm{~cm}$ plates. The medium was replaced with fresh medium $1 \mathrm{~h}$ before the transfection. The DNA/Fugene mix (ratio 1:2) was prepared in Optimem medium (Life Technologies). N2A cells were cotransfected with $1.5 \mu \mathrm{g}$ of pCAGGs-Cas9(BB)-2A-GFP-gRNA $\#(\mathrm{n})$ and $2.2 \mu \mathrm{g}$ of the associated repair template. Cells plated on different wells were transfected with different gRNAs. Cells were incubated at $37^{\circ} \mathrm{C}$ in a $5 \% \mathrm{CO}_{2}$ humidified atmosphere for $48 \mathrm{~h}$ following transfection, then detached using Trypsin-EDTA $0.25 \%$ (Sigma-Aldrich), and prepared for fluorescent activated cell sorting (FACS).

\section{Animal Handling}

Mice pups and adult mice (male and female) from a homozygous colony of B6.CXB1-Pde $6 b^{r d 10} / \mathrm{J}$ mice (The Jackson Laboratory) were used for the experiments. C57BL/6J mice (Charles River) were used as control group. All animals were kept in a $12 \mathrm{~h}$ day/night cycle with access to food and water ad libitum. White light (300 \pm 50 lux) was present from $7 \mathrm{AM}$ to $7 \mathrm{PM}$ and red light (650-720 nm, 80-100 lux) from 7 PM to 7 AM (light intensity measured at $1 \mathrm{~m}$ above the floor). All pups were kept with the mother until weaning, except for the time necessary to perform the subretinal injection. All the experiments were carried out during the day cycle.

\section{Preparation of Neurospheres and Nucleofection}

Primary cultures of neural stem cells (NSC) were prepared from WT and Rd10 mice (Pacey et al., 2006). Postnatal day (P) 2 mice were decapitated, and the brain was removed from the skull. The cortex and the hippocampus were isolated and cut in small cubes in the tissue dissection solution (in $\mathrm{mM}$ ): $124 \mathrm{NaCl}, 5 \mathrm{KCl}, 3.2 \mathrm{MgCl}_{2}, 26 \mathrm{NaHCO}_{3}, 10$ glucose, and $0.1 \mathrm{CaCl}_{2}$ (Sigma-Aldrich). An enzyme mix was dissolved in $30 \mathrm{ml}$ of tissue dissection solution and added: trypsin $0.04 \mathrm{~g}$, Type 1-S Hyaluronidase $0.02 \mathrm{~g}$, and kynurenic acid $0.004 \mathrm{~g}$ (Sigma-Aldrich). The tissue was incubated for $40 \mathrm{~min}$ in a water bath at $37^{\circ} \mathrm{C}$ and triturated with a Pasteur pipette every $20 \mathrm{~min}$. After centrifugation, the enzyme mix was removed and the trypsin inhibitor (Sigma-Aldrich), dissolved in serumfree medium (SFM) at the concentration of $1 \mathrm{mg} \mathrm{ml}^{-1}$, was added. The tissue was then triturated and incubated in the water bath for an additional $10 \mathrm{~min}$. After centrifugation, the tissue was resuspended in SFM containing: DMEM/F12 (Life Technologies), $20 \mathrm{ng} \mathrm{ml}^{-1}$ EGF (Peprotech), $20 \mathrm{ng} \mathrm{ml}^{-1}$ FGF (Peprotech), 2\% v/v B-27 (Life Technologies), $1.83 \mu \mathrm{g} \mathrm{ml}^{-1}$ Heparin (Sigma-Aldrich), $1 \mathrm{mM}$ Putrescine (Sigma-Aldrich),
$2 \mu \mathrm{M}$ Progesterone (Sigma-Aldrich), $10 \mu \mathrm{g} \mathrm{ml}^{-1}$ ITSS (SigmaAldrich), $6 \mathrm{mg} \mathrm{ml}^{-1}$ glucose (Sigma-Aldrich), and 1\% Pen/Strep (Life Technologies). Then, the tissue was triturated to obtain a single-cell solution. The cells were counted with the vital dye Trypan blue (Sigma-Aldrich) and then plated at 100.000 cells in each well of a 12-well non-coated plate. We obtained neurospheres that were maintained in $\mathrm{SFM}$ at $37^{\circ} \mathrm{C}$ in a $5 \% \mathrm{CO}_{2}$ humidified atmosphere and passed 1:3 for three times a week. After 3-4 passages cell were electroporated via Nucleofection with the AMAXA nucleofection device (LONZA). The neurospheres were dissociated with Accutase (SigmaAldrich) and $5 \times 10^{6}$ NSCs were electroporated with $2 \mu \mathrm{g}$ of pCAGGs-Cas9(BB)-2A-GFP-gRNA and $2 \mu \mathrm{l}$ of repair template $(10 \mu \mathrm{M})$ following the protocol suggested by the manufacturer. Cells were then incubated at $37^{\circ} \mathrm{C}$ in a $5 \% \mathrm{CO}_{2}$ humidified atmosphere for $30 \mathrm{~h}$, dissociated with Accutase, and green fluorescent protein (GFP)-positive cells isolated by FACS.

\section{Restriction Analysis}

Cells in Hibernate-A medium were filtered (Life Technologies) and FACS-isolated with a FACSAria (BD-Biosciences). GFP positive cells were collected in a tube containing phosphate buffered saline (PBS) + fetal bovine serum $2 \%$. The genomic DNA (gDNA) of the sorted cells (both N2A and NSCs) was extracted with the Genomic DNA ${ }^{\mathrm{TM}}$ - Tissue MiniPrep kit (Zymo Research) following the protocol of the manufacturer for cell suspensions. The DNA was eluted in $30 \mu \mathrm{l}$ of DNAse-free water and concentration measured at $260 \mathrm{~nm}$ with an ND1000 Nanodrop spectrophotometer (Thermo Fisher Scientific). $125 \mathrm{ng}$ of purified gDNA was used for PCR amplification. The following primers (Sigma-Aldrich), mapping outside the ssODN sequence were used to amplify a region of $\approx 700$ bps containing the edited region of the Pde6b gene: tttctgctcacaggccacat (forward) and gctccagaaggcagtggtta (reverse). The DNA fragment obtained by amplification was purified with the PCR purification kit (QIAGEN) and quantified as above. For the restriction analysis of PCR products, $300 \mathrm{ng}$ of DNA was digested with 5 units of BanI enzyme for $1 \mathrm{~h}$ in $25 \mu \mathrm{l}$ total reaction volume. The digestion of the PCR fragment obtained amplifying unedited gDNA with the BanI restriction enzyme generated two fragments of 470 and 230 bps, respectively, that were resolved on $2 \%$ agarose gel. The PCR fragments obtained amplifying the edited gDNA could not be digested by the BanI enzyme, thus leaving the undigested 700 bps fragment on an agarose gel. The optical density of the 700-bps band was measured using the gel tool of ImageJ.

\section{Plasmids and DNA Preparation for in vivo Delivery}

The nanoplasmids expressing eGFP and Cas9/GFP were purchased from Nature Technology, and the template repair was purchased from Integrated DNA Technologies. The gRNA was cloned into the pSPgRNA plasmid (\#47108, Addgene). All the components used for the in vivo experiments are specified in Table 2.

The following are the specific solutions used for each experiment (all of them were prepared in PBS with the addition of $0.1 \%$ Fast green for the visualization of the injection): 
- eGFP preparation: eGFP-coding plasmid $\left(1 \mu \mathrm{g} \mu \mathrm{l}^{-1}\right)$.

- Cas9 preparation: Cas9-coding plasmid (1 $\mu g$ $\left.\mu \mathrm{l}^{-1}\right)+$ gRNA-coding plasmid $\left(0.45 \mu \mathrm{g} \mu \mathrm{l}^{-1}\right)+$ repair $\operatorname{ssODN}\left(2 \mu \mathrm{l} \mu \mathrm{g}\right.$ of $\left.\mathrm{Cas}^{-1}\right)$.

- Sham preparation: Cas9-coding plasmid (1 $\mu \mathrm{g}$ $\left.\mu \mathrm{l}^{-1}\right)+$ repair ssODN $\left(2 \mu \mathrm{l} \mu \mathrm{g}\right.$ of Cas $\left.9^{-1}\right)$.

- Cas9 + eGFP (1.5:1) preparation: Cas9-coding plasmid $\left(1.5 \mu \mathrm{g} \mu \mathrm{l}^{-1}\right)+$ gRNA-coding plasmid $(0.8 \mu \mathrm{g}$ $\left.\mu \mathrm{l}^{-1}\right)+$ eGFP-coding plasmid $\left(0.9 \mu \mathrm{g} \mu \mathrm{l}^{-1}\right)+$ repair $\operatorname{ssODN}\left(2 \mu \mathrm{l} \mu \mathrm{g}\right.$ of $\left.\mathrm{Cas}^{-1}\right)$.

\section{Subretinal Injection and Electroporation}

Subretinal injections were performed in mice pups at P3, P8, or both. The pups were anesthetized using isoflurane $(0.8-1.51$ $\min ^{-1}$ at $\left.3 \%\right)$ in an induction box, then placed onto a sterile paper towel under a microscope; the anesthesia was maintained with isoflurane $\left(0.8-1.5 \mathrm{l} \mathrm{min}^{-1}\right.$ at $\left.2 \%\right)$, and the temperature was maintained at $37^{\circ} \mathrm{C}$ with a heating pad. The skin over the eyelid was disinfected with Betadine, and a sterile $30-\mathrm{G}$ needle was used to cut the skin on the mark of the future eyelid aperture. The skin was gently pushed to the side with a pair of sterile forceps to expose the eyeball. A glass capillary (ORIGIO) backfilled with the DNA solution was insert into the subretinal space, maintaining a $45^{\circ} \mathrm{C}$ inclination to the surface of the eye. The DNA solution was then injected into the subretinal space for $3 \mathrm{~s}$ at $300 \mathrm{hPa}$ using an automatic injector (Eppendorf). Two injections were performed in the following directions: dorsal to nasal and ventral to nasal. Immediately after the DNA injection, an electric field was applied to the area using a P5 tweezer electrode (Sonidel) pre-soaked in PBS. The positive terminal was attached to the sclera of the injected eye, while the other side of the tweezer (negative terminal) was placed on the not-injected eye. The pulses were delivered using a CUY21SC electroporator (Sonidel). A conductive gel was placed between the electrode plate and the eye to maximize the conductivity and minimize burns on the cornea. Two square pulses of $5 \mathrm{~ms}$ at $100 \mathrm{~V}$ were applied with $0.1 \mathrm{~Hz}$ frequency (poring pulses), followed by five pulses of $50 \mathrm{~ms}$ at $30 \mathrm{~V}$ with $1 \mathrm{~Hz}$ frequency (transfer pulses). After the procedure, the eyelid was closed gently with a cotton swab, and the pup was placed onto a heating pad at $37^{\circ} \mathrm{C}$ until fully

TABLE 2 | Full name, size, and origin of all the components used in the in vivo experiments.

\begin{tabular}{llll}
\hline Component & Name & Length & Supplier \\
\hline eGFP plasmid & NTC9385R-eGFP & $2391 \mathrm{bp}$ & $\begin{array}{l}\text { Nature } \\
\text { Technology }\end{array}$ \\
Cas9 plasmid & NTC9385R-CAGCas9- & $6500 \mathrm{bp}$ & $\begin{array}{l}\text { Nature } \\
\text { Technology }\end{array}$ \\
gRNA plasmid & T2A-GFP & & Addgene \\
Repair template & SSODN & $3000 \mathrm{bp}$ & IDT \\
& & 200 & \\
\end{tabular}

The concentrations were adjusted in order to have the same number of copies of guide-coding and Cas9-coding plasmids, taking into account the relative number of base pairs. The repair SSODN concentration is similar to what previously described for CRISPR-Cas9 editing systems. recovered, then returned to the mother. In all the groups the injection was performed unilaterally in order to keep the other eye as an internal control. The pups were treated daily during the first-week post-surgery with Tobradex eye drops (tobramycin $0.3 \%$ and dexamethasone $0.1 \%$ ) on the operated eye.

\section{Retina Sections, Wholemounts, and Immunohistochemistry}

After euthanasia by $\mathrm{CO}_{2}$ inhalation, the eyes of the mice were extracted from the ocular cavity using forceps, washed in PBS, and fixed in $4 \%$ paraformaldehyde overnight. For wholemount preparation, the retina was extracted, and cut in 4 points in order to flat it on a microscope slide. For section preparation, the samples were cryoprotected in sucrose $30 \%$ and frozen in optimal cutting temperature compound (Tissue-Tek ${ }^{\circledR}$ ). $20 \mu \mathrm{m}$ thick sections of the retina were obtained using a Histocom cryostat (Thermo Fisher Scientific) and placed on microscope slides. The wholemounts were washed in PBS, permeabilized with PBS + Triton $0.1 \%$ (Sigma-Aldrich), counterstained with DAPI 1:300 (Sigma-Aldrich), and mounted for imaging with Fluoromount (Sigma-Aldrich). Retinal sections were washed in PBS, permeabilized with PBS + Triton $0.1 \%$, left for $1 \mathrm{~h}$ at room temperature in blocking buffer (Triton $0.1 \%+5 \%$ normal goat serum), and incubated overnight at $4^{\circ} \mathrm{C}$ with primary antibodies: anti-rhodopsin 1:300 (ab221664, Abcam) and anti-GFP 1:1000 (ab13970, Abcam). The day after the sections were incubated for $2 \mathrm{~h}$ at room temperature with secondary antibodies 1:500 (Alexa Fluor 647 and 488, Abcam), counterstained with DAPI 1:300, and mounted for imaging with Fluoromount solution. Image acquisition was performed with a confocal microscope (LSM-880, Zeiss).

\section{Droplet-Digital PCR}

The eyes of P6 mice electroporated at P3 were enucleated, and the retina was immediately isolated in ice-cold PBS and quickly inspected under a fluorescence microscope to verify eGFP expression. The gDNA was extracted using the Genomic $\mathrm{DNA}^{\mathrm{TM}}$ - Tissue MiniPrep kit (Zymo Research) following the protocol of the manufacturer for solid tissues. The DNA was eluted in $30 \mu \mathrm{l}$ of DNase-free water. To avoid possible false-positive signals in droplet digital PCR (ddPCR) from unintegrated ssODN repair template, we optimized a nestedddPCR assay. We first pre-amplified from extracted gDNA by conventional PCR a fragment of $\approx 700$ bps containing the edited region of the Pde6b gene with primers mapping outside the ssODN sequence (same as for the BanI restriction assay). The amplified DNA fragment was purified and quantified as above. Next $2.5 \mathrm{fg}$ of the purified template (corresponding to $\approx$ 3500 copies of target DNA) was used in the ddPCR assay with internal primers (Fwd: CAGCAAAGCCTATCGAAGAATCA; Rev: CATGGTCTGGGCTACATTGAAG) and detected with an edited-specific TaqMan ${ }^{\circledR}$ probe (FAM- TATCACAACTGGAGAC AC-MGB) and an unedited-specific $\mathrm{TaqMan}^{\circledR}$ probe (VICTACCACAACTGGTGCCA-MGB). Reactions were assembled with ddPCR ${ }^{\mathrm{TM}}$ Supermix for Probes (Bio-Rad Laboratories) and partitioned into nanoliter-sized droplets with QX200 Droplet 
Generator (Bio-Rad Laboratories). After PCR thermal cycling, droplets for each sample were individually read on a QX200 Droplet Reader (Bio-Rad Laboratories) and assigned as positive or negative based on fluorescence amplitude.

\section{Recordings of Microelectroretinograms ex vivo}

P60 mice electroporated at P3 were dark-adapted overnight before tissue collection. All procedures were performed under dim red light. Retinas were explanted after euthanasia by intraperitoneal injection of sodium pentobarbital $\left(150 \mathrm{mg} \mathrm{kg}^{-1}\right)$. The retinas were dissected in carboxygenated $\left(95 \% \mathrm{O}_{2}\right.$ and $5 \%$ $\mathrm{CO}_{2}$ ) Ames' medium (A1420, Sigma-Aldrich). After dissection of the sclera, the retina was detached from the pigment epithelium, and the vitreous humor was removed. The retina was then cut into pieces (approximately $5 \mathrm{~mm}^{2}$ ), attached to a filter paper, and transferred onto a multielectrode array (MEA; 256MEA200/30iRITO, Multi Channel Systems) with the ganglion cell layer facing the electrodes. Explanted retinas were continuously superfused with carboxygenated Ames's medium at $32^{\circ} \mathrm{C}$. Data acquisition, amplification, and digitalization were performed with a recording system (USB-MEA256-System; Multi Channel Systems) placed on the stage of an inverted Ti-E microscope (Nikon Instruments). The microscope was equipped with a dichroic filter (FF875Di01-25 × 36; Semrock) and a $4 \mathrm{x}$ objective (diameter of the illumination spot $5.5 \mathrm{~mm}$; CFI Plan Apochromat Lambda). Light stimuli were provided by an attached Spectra $\mathrm{X}$ system (Emission filter 560/32; Lumencor). Ten consecutive pulses of $4 \mathrm{~ms}$ and $0.5 \mathrm{~mW} \mathrm{~mm} \mathrm{~mm}^{-2}$ were delivered at a repetition rate of $1 \mathrm{~Hz}$. The extracellularly recorded signals were digitalized and stored for offline analysis. Data filtering and spike sorting were performed using the MC_Rack software (Multi Channel Systems). The presence of spontaneous spiking activity was assessed (filter 300$3000 \mathrm{~Hz}$, sampling rate of $25 \mathrm{kHz}$ ) to ensure the viability of the retinal explant. Only retinas showing spontaneous activity in at least one channel when placed on the MEA were selected for recordings, and each responding channel was treated as an independent unit. To detect $\mu$ ERGs, the signal was filtered from 0.5 to $100 \mathrm{~Hz}$ and digitalized at $10 \mathrm{kHz}$. The prominence of the microelectroretinograms ( $\mu$ ERGs) a-wave was computed for each channel in MATLAB (MathWorks).

\section{Recording of Electroretinograms in vivo}

Before the recording sessions, P30 mice were dark-adapted overnight. The mice were then anesthetized with isoflurane $(0.8-$ $1.51 \mathrm{~min}^{-1}$ at $4 \%$ for induction and $0.8-1.51 \mathrm{~min}^{-1}$ at $1.5 \%$ for maintenance). The depth of anesthesia was assessed with the pedal reflex, and artificial tears were used to prevent the eyes from drying. The temperature was maintained at $37^{\circ} \mathrm{C}$ with a heating pad. The pupils were dilated with a drop of Atropine 1\%. The recordings were performed in both eyes simultaneously using two custom-made platinum loop electrodes placed in contact with the eyes and kept in place with a small drop of conductive gel. A needle electrode was placed subcutaneously in the dorsal area near the tail as ground. Five light flashes $\left(4 \mathrm{~ms}, 30 \mathrm{~cd} \mathrm{~s} \mathrm{~m}^{-2}\right.$, $0.1 \mathrm{~Hz}$ repetition rate) were delivered with a Ganzfeld stimulator
(BM6007IL, Biomedica Mangoni) positioned close to the mice and the corresponding retinal potentials were amplified, filtered $(0.1-500 \mathrm{~Hz})$, and digitalized for $500 \mathrm{~ms}(50 \mathrm{~ms}$ pre-stimulus and $450 \mathrm{~ms}$ post-stimulus) at $8 \mathrm{kHz}$ (BM623, Biomedica Mangoni). The data were analyzed using MATLAB.

\section{Measurement of the Visual Acuity}

The optomotor system (Cerebral Mechanics) was used for the measurement of the visual acuity. Control and treated mice were habituated for 5 min placing them in the center of the virtual arena the day before the beginning of the test. The day of the test, each mouse was placed on the platform, and the program started. The mouse in the arena was presented with a grating stimulus rotating in either direction, and the operator had to decide if the mouse was tracking or not the rotating stimulus with a movement of the head in the same direction of the rotation. The program uses a built-in algorithm based on a staircase method to evaluate the visual threshold of the two eyes independently. Since each eye tracks a rotating stimulus only with a temporal-to-nasal movement, the visual acuity can be measured independently for each eye by controlling the direction of rotation of the stimulus. Shortly, clockwise movements represent the left eyedriven tracking behavior (hence the visual acuity of the left eye), while anticlockwise movements represent the right eye-driven tracking behavior (Thomas et al., 2004; Douglas et al., 2005). Similar patterns were observed in optokinetic eye movements in rabbits (Hobbelen and Collewijn, 1971) and rats (Harvey et al., 1997). The performance of any single mouse was assessed during three subsequent days, and the resulting average was considered the value of the mouse visual threshold. Mice were tested at $\mathrm{P} 30, \mathrm{P} 60$, and $\mathrm{P} 90$.

\section{Electrode Implantation and Recording of Visually Evoked Potentials}

Before the surgical procedures and the recording sessions, the mice were anesthetized with isoflurane $\left(0.8-1.51 \mathrm{~min}^{-1}\right.$ at $4 \%$ for induction and $0.8-1.51 \mathrm{~min}^{-1}$ at $1.5 \%$ for maintenance). Analgesia was administered by subcutaneous injection of Buprenorphine (Temgesic, $0.1 \mathrm{mg} \mathrm{kg}^{-1}$ ) followed by subcutaneous injection of a mix composed by lidocaine $(6 \mathrm{mg}$ $\left.\mathrm{kg}^{-1}\right)$ and bupivacaine $\left(2.5 \mathrm{mg} \mathrm{kg}^{-1}\right)$ with a $1: 1$ ratio. The depth of anesthesia was assessed with the pedal reflex, and artificial tears were used to prevent the eyes from drying. The temperature was maintained at $37^{\circ} \mathrm{C}$ with a heating pad during both surgical and recording sessions. For electrode implantation, anesthetized P60 mice mounted on a stereotaxic apparatus. The skull was exposed for the visualization of lambda, and the skin was pulled on the side. Two screw electrodes were implanted $3 \mathrm{~mm}$ lateral to lambda over the left and right visual cortices. A reference electrode was placed in the rostral side of the cranium, outside of the visual cortex. The electrodes were fixed using dental cement. The screws were then left in place for 30 more days. The surgery was performed in advance in order to let the electrodes to stabilize. For recordings, all the procedures were performed under dim red light. P90 mice were dark-adapted overnight, anesthetized, and mounted on a stereotaxic frame. The 
pupils were dilated with a drop of Atropine 1\%, and a needle electrode was placed subcutaneously in the dorsal area near the tail as ground. The recordings were acquired simultaneously in two channels connected to the two electrodes implanted on both visual cortices. Three light flashes $\left(4 \mathrm{~ms}, 10 \mathrm{~cd} \mathrm{~s} \mathrm{~m}^{-2}\right.$, interleaved by $2 \mathrm{~min}$ ) were delivered with a Ganzfeld stimulator (BM6007IL, Biomedica Mangoni) positioned close to the mice and the corresponding visually evoked cortical potentials were amplified, filtered $(0.1-500 \mathrm{~Hz})$, and digitalized for $1000 \mathrm{~ms}$ (50 ms pre-stimulus and $950 \mathrm{~ms}$ post-stimulus) at $2 \mathrm{kHz}$ (BM623, Biomedica Mangoni). The data were analyzed using MATLAB.

\section{Statistical Analysis and Graphical Representation}

Statistical analysis and graphical representation were performed with Prism (GraphPad Software Inc.). The normality test (D’Agostino \& Pearson omnibus normality test) was performed in each dataset to justify the use of a parametric ( $t$-test and One-Way ANOVA) or non-parametric (Kruskal-Wallis and Mann-Whitney) test. The fitting of the visually evoked cortical potentials (VEPs) was performed with the non-parametric Kernel distribution in MATLAB. In each figure p-values were represented as: ${ }^{*} p<0.05,{ }^{* *} p<0.01$, ${ }^{* * *} p<0.001$, and $* * * * p<0.0001$.

\section{RESULTS}

\section{gRNA Screening and High Editing Efficiency of the CRISPR-Cas9 Vector in Cell Culture}

The efficiency of different gRNAs in inducing HDR-mediated editing of a specific genomic locus can be very different, ranging from 0.7 to 30\% (Cong et al., 2013; Ran et al., 2013). Therefore, as a first step in the development of the gene editing system, we designed and screened different gRNAs for their ability to induce CRISPR/Cas9-mediated editing of the Pde6b gene. We selected three candidate gRNAs and screened them in mouse $\mathrm{N} 2 \mathrm{~A}$ cells to determine which one was the best at targeting the sequence coding for WT Pde6b. We transfected N2A cells with a single plasmid, containing Cas9, one of the three gRNAs, and GFP, along with a DNA ssODN repair template specific for each gRNA, containing flanking sequences of 100 bp on each side of the insertion site that were homologous to the target region. The gRNA \#1 and gRNA \#3 mapped upstream and downstream to the Rd10 locus, while the gRNA \#2 mapped directly on it (Figure 1A). Each repair template for HDR-mediated editing was designed to edit the gDNA sequence at the Rd10 locus and simultaneously remove an adjacent cutting site for the restriction enzyme BanI (by introducing a silent mutation), allowing the assessment of the editing efficiency by BanI restriction analysis (Figure 1A). Moreover, each repair template also carried a second specific silent mutation in the PAM sequence of the corresponding gRNA to avoid further Cas9-mediated cutting on the edited genomic sequence (Figure 1A). One day after transfection, we isolated GFP-expressing cells by FACS, extracted the gDNA and PCR-amplified a 700 bp fragment containing the $P d e 6 b$ target region with primers mapping outside the ssODN homology arm sequence (Figure 1A). After BanI digestion and agarose-gel electrophoresis, the edited DNA appeared as a single uncut band (700 bp), while non-edited DNA was digested in two fragments ( 230 and $470 \mathrm{bp}$ ). The quantification of the percentage of edited vs. non-edited DNA for each gRNA showed that gRNA \#2 had the highest editing efficiency and was the best performing gRNA (Figures 1B,C). Based on this result, we next designed for the final editing tool gRNA \#4 which differ from gRNA \#2 only in a single base pair (Figure 1D), corresponding to the $\mathrm{C}$ to $\mathrm{T}$ mutation found in the mutated Pde6b gene of Rd10 mice. We further verified gRNA \#4 editing efficiency in NSC derived from Rd10 homozygous pups. The transfected Rd10 cells were selected for GFP-expression with FACS and the editing efficiency was evaluated by BanI restriction assay, as described above for N2A cells. We found a mean ( \pm SD, $n=3)$ net editing efficiency of $39.3 \pm 6.4 \%$ in NSC harboring the Rd10 mutation (Figures 1E,F). These data indicate that the selected gRNA \#4 efficiently targets the Rd10 mutation in the Pde6b gene and that the correct sequence can be restored with high efficiency by CRISPR/Cas9-mediated HDR editing.

\section{Efficient Delivery of a Reporter Gene to Photoreceptor Cells by in vivo Electroporation}

The efficiency of electrotransfer depends on various factors such as the cell size, the parameters of the electric pulses, and the phase of the cell cycle. The latter has to be taken into account especially when interested in targeting the highest number of cells and in exploiting the HDR mechanism to achieve gene editing. In order to obtain the highest number of transfected cells without inducing eye defects, we performed pilot experiments to optimize the electroporation protocol and select the best timing for delivery. Although electroporation immediately after birth is potentially more efficient, it can result in eye damage: in our hand, P1 electroporation resulted in more than $50 \%$ of the pups bearing eye defects as adults, while this percentage was reduced at $40 \%$ by performing electroporation at P3 (at the peak of the photoreceptor proliferation curve). For this reason, P3 was selected for the in vivo experiments (Figure 2A, dashed line). Moreover, several groups reported efficient retinal electroporation in neonatal mice using five pulses of $50 \mathrm{~ms}$ at $80 \mathrm{~V}$ (1 Hz) (Matsuda and Cepko, 2004; de Melo and Blackshaw, 2011), but we found this protocol to cause eye defects (possibly affecting visual functions) in $40 \%$ of the adult mice when the electroporation was performed at P3. Thus, based on previous observations in cell cultures (Bureau et al., 2000), we tested a different protocol (Figure 2B) consisting of two short poring pulses at high voltage $(5 \mathrm{~ms}, 100 \mathrm{~V}, 0.1 \mathrm{~Hz}$ ) followed by five long transfer pulses at a lower voltage $(50 \mathrm{~ms}, 30 \mathrm{~V}, 1 \mathrm{~Hz})$. Applying this improved protocol, we obtained an electroporation efficiency comparable to the standard protocol, whereas the number of pups bearing eye defects when adults decreased from 40 to $5 \%$; those animals were excluded from the experiments. Also, the use of a conductive gel between the electrode plate and the tissue 


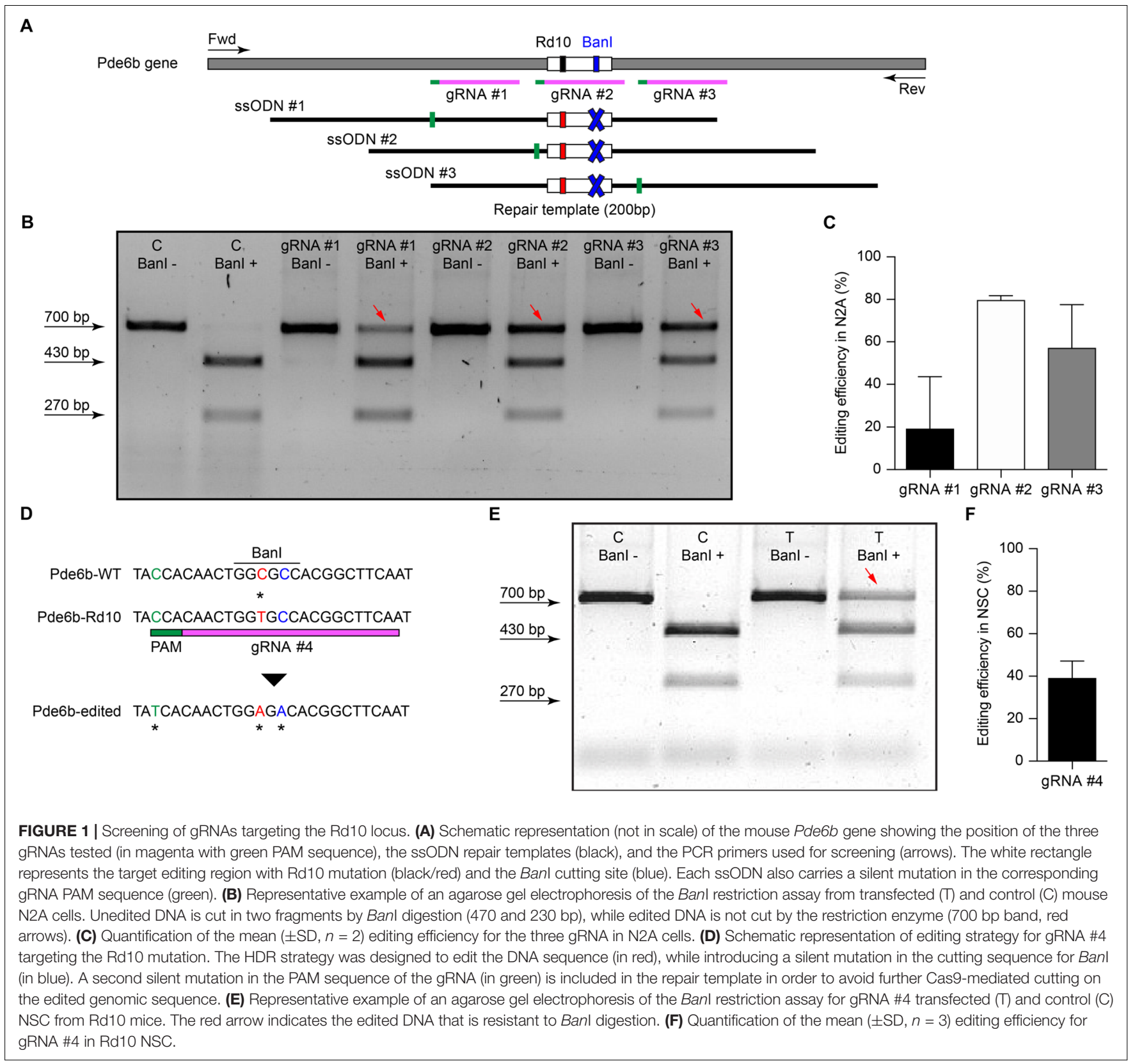

increased the conductivity and avoided burning marks on the cornea. In order to assess the efficiency of electroporation in targeting the photoreceptor cell progenitors in vivo, we delivered a plasmid coding for eGFP to the subretinal space of $\mathrm{Rd} 10$ mouse pups with two consecutive subretinal injections followed by electroporation at P3 (Figure 2C). The image sequence shows that eGFP was expressed at all the different stages of retinal development at which the retinas were isolated: P5, P10, and P15 ( $n=6$ at each time point). At P5, most of the expressing cells were confined to the ventricular zone, where the photoreceptor progenitors proliferate. At P10, the cells started to migrate toward the photoreceptor layer, which they finally reached by P15. The electroporation targets mostly photoreceptors due to their proximity to the injection site, but it is not completely specific to this cell type; indeed, we observed some bipolar and ganglion cells expressing eGFP. This eventuality does not represent a concern for the outcome of the therapy since the targeted gene is expressed specifically in rod photoreceptors. To analyze the extension of the electroporated zone, we prepared wholemount retinas from the treated mice (Figure 2D). In a few cases ( 2 out of 6 ) the two consecutive injections per eye resulted in two electroporated areas and all the other cases in one area only, with a single area covering up to $25 \%$ of the retina. The localization of the electroporated cells depends on the orientation of the electric field to the injection site at the moment of the electroporation, which is challenging 


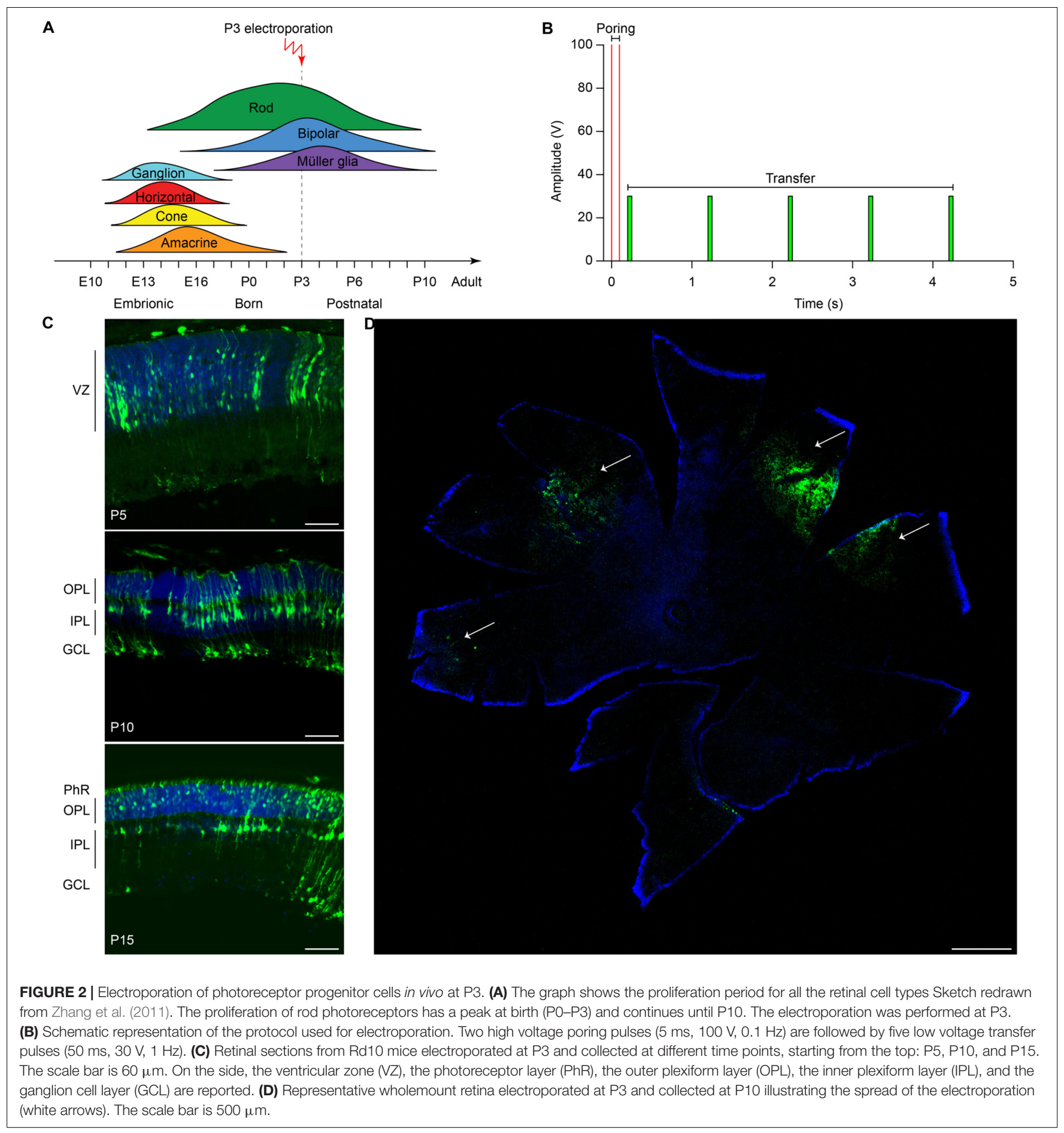

to control in an animal as small as the mouse, especially at this young age.

\section{Significant Editing Efficiency in vivo of the CRISPR-Cas9 Editing Tool}

Evaluating editing efficiency in whole retinas in vivo is a more challenging task than in vitro due to the presence of a mixed population of transfected and non-transfected cells. To this aim, we developed a sensitive ddPCR assay with two fluorescent probes specific for the edited and unedited alleles (Figure 3A). Rd10 pups were electroporated at P3 with plasmids encoding eGFP, Cas9, gRNA \#4, together with the ssODN repair template. Sham electroporation of control retinas in Rd10 pups at P3 was performed by omitting the gRNA. Three days after electroporation, we extracted the gDNA 
from whole retinas and analyzed the editing efficiency at the $P d e 6 b$ gene by ddPCR. We found that the mean $( \pm S D$, $n=10)$ in vivo editing efficiency in $\mathrm{Rd} 10$ treated retinas was $0.221 \pm 0.141 \%$ and significantly different from $\mathrm{Rd} 10$ sham retinas $(p<0.05$, unpaired $t$-test) that however, showed a low but detectable background ( $0.057 \pm 0.050 \%, n=6)$ in the assay (Figure 3B). The normalized editing efficiency after subtracting the detectable background is $0.164 \pm 0.141 \%$. Although in vivo editing efficiency appeared much lower than in vitro, this represents an underestimation because the assay was conducted on gDNA extracted from whole retinas that contained only a relatively small percentage of transfected cells. Moreover, treated retinas showed variable degrease of editing, likely due to a difference in electroporation efficiency. However, even a few functional photoreceptors can make a large difference when it comes to visual performance (MacLaren et al., 2006; Tucker et al., 2011).

We also performed a staining for rhodopsin and GFP on retinal sections from P30 Rd10 mice electroporated at P3. This result shows preservation of rhodopsin in the outer segment of photoreceptors in the treated eyes in concomitance with electroporated cells (Figure 3C).

\section{Gene Editing Preserves Electroretinograms ex vivo and in vivo}

To verify whether the extent of gene editing can translate to improved retinal functionality, we recorded the microelectroretinograms ( $\mu$ ERGs) from explanted retinas of P60 Rd10 mice that were electroporated at P3 (Figure 4A). Untreated Rd10 mice were used as control. Previous results show that Rd10 retinas are completely degenerated (Jae et al., 2013) and stop consistently responding to light stimulation at P60 (Stasheff et al., 2011). We recorded simultaneously from all the electrodes of a MEA while stimulating using green light pulses $\left(4 \mathrm{~ms}, 0.5 \mathrm{~mW} \mathrm{~mm}^{-2}\right.$ ). In Figure 4B, we present a representative $\mu E R G$ response from a treated retina, as the average over ten sequential stimulations delivered at $1 \mathrm{~Hz}$ of repetition rate. The a-wave peak amplitudes in Rd10 treated retinas are significantly higher $(p<0.0001$, unpaired $t$-test) than $\mathrm{Rd} 10$ untreated retinas (Figure $4 \mathrm{C}$ ). This result supports our hypothesis that the functionality of the retina is preserved in $\mathrm{Rd} 10$ treated mice.

We then verified to which extent our results ex vivo could effectively lead to functional improvement in vivo. In the Rd10 mouse the degeneration of rod photoreceptors starts at 2 weeks of age and peaks at 4 weeks of age. The thickness of the outer nuclear layer abruptly drops from P20 to P25, which translates into the almost complete absence of the electroretinogram (ERG) responses by P30 (Gargini et al., 2007). Based on this evidence, we recorded ERGs at P30 in Rd10 mice unilaterally treated (at P3) and WT mice upon ganzfeld flash stimulation (Figure 4D). In Figure 4E, representative ERG responses (average of 5 sweeps) are shown for the treated (blue) and untreated (black) eyes in Rd10 mice and for both eyes (gray) in WT mice. We then compared the a-wave amplitude in $\mathrm{Rd} 10$ mice (Figure 4F) and WT mice (Figure 4G), which correlates directly with the functionality of photoreceptors (Pinto et al., 2007). These results suggest a preserved photoreceptor functionality in the eyes treated at P3 of Rd10 mice compared to the control eye $(p<0.01$, paired $t$-test). As expected, in WT mice there is no significant difference between the a-wave of the left and right eye ( $p=0.1751$, paired $t$-test). In eyes treated at P3, the average b-wave is also larger than the control eyes (mean \pm SD, $75.20 \pm 47.85$ and $44.95 \pm 46.20$ respectively, for treated and control eyes) but the difference is not statistically significant ( $p=0.1449$, paired $t$-test). In WT mice, there is no significant difference between the b-wave of the left and right eye ( $p=0.2373$, paired $t$-test).

\section{Gene Editing Preserves Visual Acuity in vivo Until P90}

Next, we assessed the visual acuity of Rd10 unilaterally treated (at P3), Rd10 unilaterally sham-treated (at P3), Rd10 untreated, and WT adult mice using a behavioral assay. The optomotor test, which measures the integrity of the subcortical visual pathways, uses the amplitude of the optomotor reflex to evaluate the visual acuity of rodents (Figure 5A). In particular, it allows the distinction between right eye-driven and left eyedriven responses, measuring the visual threshold of each eye independently (Douglas et al., 2005). At P30 (about 1 month after treatment), in Rd10 mice, the treated eye (Figure 5B, white circles) showed a higher visual acuity compared to the paired untreated eye (treated $0.24 \pm 0.01 \mathrm{C} /{ }^{\circ}$, untreated $0.14 \pm 0.01$ $\mathrm{C} /{ }^{\circ} ; n=71, p<0.0001$, Mann-Whitney test). Conversely, the Rd10 sham-treated eye (light gray circles) did not show any improvement compared to the paired untreated eye (sham $0.11 \pm 0.01 \mathrm{C} /{ }^{\circ}$, untreated $0.13 \pm 0.01 \mathrm{C} /{ }^{\circ} ; n=20, p=0.2306$, unpaired $t$-test). In both WT (left $0.41 \pm 0.01 \mathrm{C} /{ }^{\circ}$, right $0.39 \pm 0.01 \mathrm{C} /{ }^{\circ} ; n=32, p=0.1009$, Mann-Whitney test; black dots) and $\mathrm{Rd} 10$ (left $0.12 \pm 0.01 \mathrm{C}{ }^{\circ}$, right $0.11 \pm 0.01$ $\mathrm{C} /{ }^{\circ} ; n=47, p=0.4908$, unpaired $t$-test; dark gray dots) mice no difference was detected between the left and right eyes (Figure 5B). Measures of the optomotor reflex (Figure 5C) demonstrated that the average visual acuity in the treated eyes of $\operatorname{Rd} 10$ mice is significantly higher than the average visual acuity of both Rd10 mice ( $p<0.0001$; One Way ANOVA, Tukey's multiple comparisons test) and sham-treated eyes in Rd10 mice $(p<0.0001$; One Way ANOVA, Tukey's multiple comparisons test). Sham-treated eyes have a visual acuity not statistically different from Rd10 mice's eyes $(p=0.9849$; One Way ANOVA, Tukey's multiple comparisons test). Since it was not measured in dark-adapted conditions, the outcome of the optomotor test is essentially related to the integrity of cone cells and direction-selective retinal ganglion cells. However, the visual acuity measured with this test is reportedly decreasing in Rd10 mice, already starting from P30 (Prusky et al., 2004), which matches our data from control and sham mice. We can thus attribute any further preservation of visual acuity to a protective effect of the treatment.

We next investigated whether the same treatment could be effective at a later stage of photoreceptor differentiation. To this end, we treated mice at P8 (Figure 6A), approximately at the end of the progenitor cells proliferation curve (Zhang et al., 2011). Electroporation at P8 did not result in any eye damage. After the 


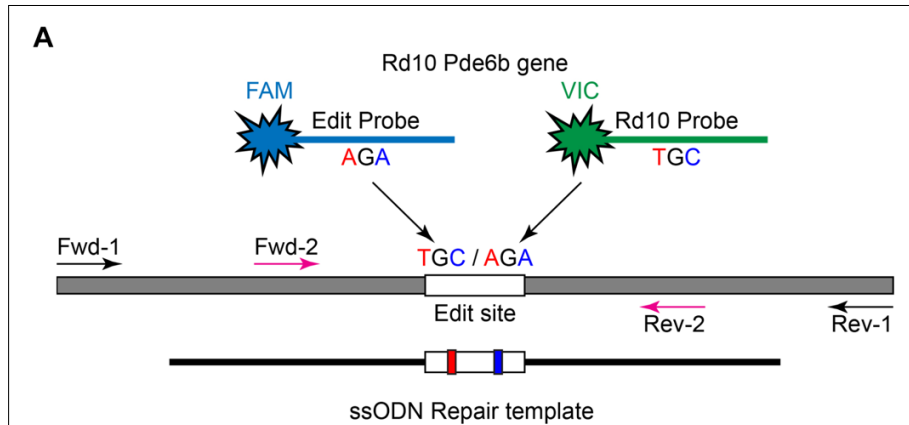

B
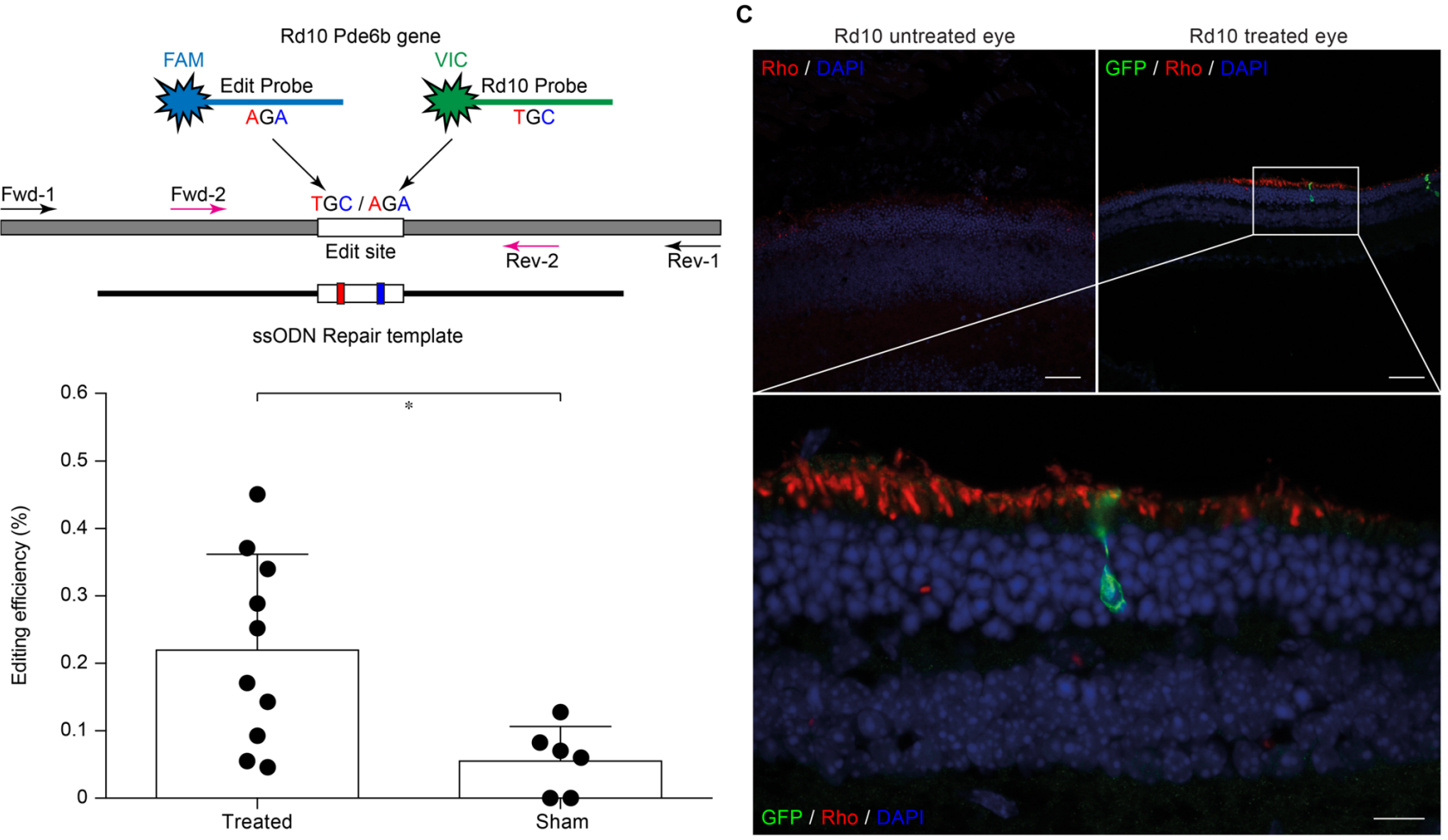

FIGURE 3 | Editing efficiency in vivo and rhodopsin staining in electroporated retinas. (A) Schematic representation of the ddPCR assay used to quantify in vivo editing efficiency. The Pde6b gene is in gray and the ssODN repair template in black (not in scale). The white rectangle represents the target editing region. Black and magenta arrows indicate primers pairs used for the nested-ddPCR. Red and blue letters indicate base mismatches detected by the two specific fluorescent probes for the edited and unedited alleles (blue and green, respectively). (B) Quantification of the mean ( \pm SD) percentage of editing in Rd10 treated retinas. (C) Retinal section from Rd10 mice electroporated at P3, collected at P30, and stained for rhodopsin (Rho, red), GFP (green), and DAPI (blue). Scale bars: top left and top right $25 \mu \mathrm{m}$; bottom $10 \mu \mathrm{m}$.

electroporation at P8, the eGFP fluorescence could be detected in retinas of $\mathrm{P} 10$ and $\mathrm{P} 15$ mice (Figures $6 \mathrm{~B}, \mathrm{C}$ ).

Based on this result, we assessed the impact of the period of treatment on the optomotor reflex. We compared the optomotor reflex responses of Rd10 mice upon electroporation at P3 (Rd10 Early Treated, ET), P8 (Rd10 Late Treated, LT), or P3 and P8 (Rd10 Early/Late Treated, ELT). The first treatment corresponds to the peak of the rod's proliferation curve, the second one to the end of the curve, and the last treatment to the combination of the two (Figure 5D). As for the Rd10 ET mice (Figure 5B), also for the Rd10 LT (Figure 7A) and the Rd10 ELT (Figure 7B), the visual acuity measured in the treated eyes was significantly higher than the visual acuity of the paired untreated eyes. Conversely, in Rd10 Early/Late Sham (Rd10 ELS) treated mice the visual acuity was not different between injected and not injected eyes (Figure 7C).

Last, we verified the long-term preservation of visual acuity by repeating the optomotor test at P60 and P90. Interestingly, while the visual acuity dropped drastically in untreated and sham-treated Rd10 mice at P60, it did not show a significant decline in any of the treated groups (Figure 5E). At P90, the visual acuity eventually decreased also in treated mice, but overall all the treated groups retained about $50 \%$ of their initial value (Figure $\mathbf{5 F}$ ). This result shows a preserved functionality of subcortical visual pathways up to 3 months in treated mice at both P3 and P8.

\section{Gene Editing Preserves Flash-Evoked Cortical Responses at P90}

To assess the functionality of the retino-cortical visual pathway, we recorded VEPs from both hemispheres upon flash stimulation. In Figure $\mathbf{8 A}$, we show a representative trace for each experimental group. For treated and sham-treated Rd10 mice, the representative recordings are relative to the cortex contralateral to the injected eye, since in the mouse the majority of the projections decussate at the optic chiasm (Coleman et al., 2009). Since we cannot exclude completely the input coming from the untreated eye (ipsilateral projection), we compared the results of the treated mice with the ones from $\mathrm{Rd} 10$ and sham-treated animals to isolate the contribution of the therapy. The mean prominence of the response's peaks was computed. At P90, Rd10 animals show a complete retinal degeneration with very few spared photoreceptors (Gargini et al., 2007; Pennesi et al., 2012). Accordingly, we observed an almost flat response in untreated (Rd10) and sham-treated (Rd10 ES and Rd10 ELS) mice. Conversely, when recording from all the treated groups (Rd10 ET, Rd10 LT, and Rd10 ELT), we observed preservation of 


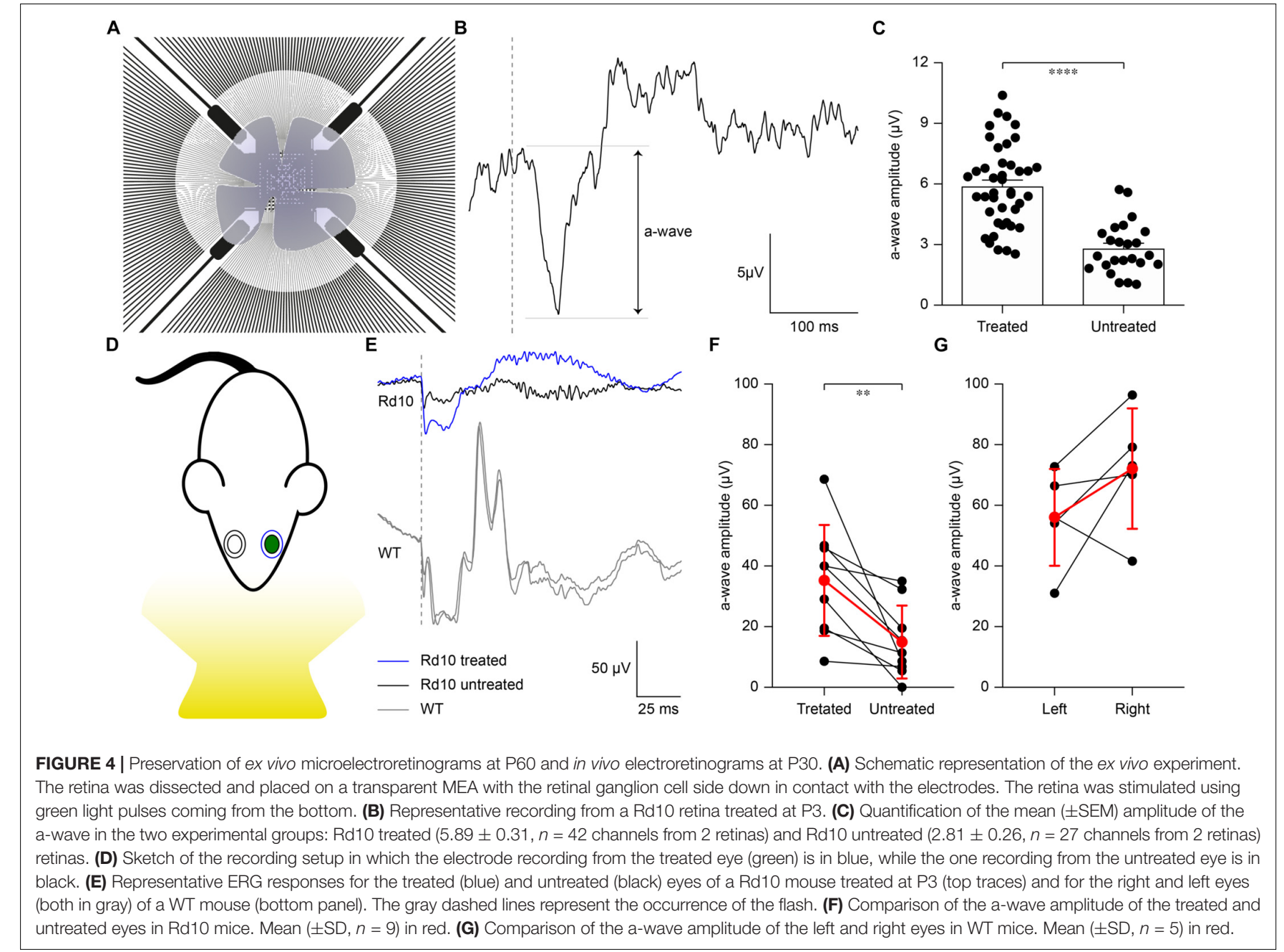

C

the peak prominence in the visual response of the contralateral cortex (Figure 8B). This is indicative of a preserved functionality of cortical visual pathways ( $p<0.0001$; Kruskal-Wallis, Dunns multiple comparison test). In the ipsilateral cortex (Figure 8C), the only significant difference was between WT and Rd10 ( $p<0.01$; Kruskal-Wallis, Dunns multiple comparison test).

Finally, we further compared the scaled probability density functions (Figure 9) of the VEP prominences in the treated (Figure 8D) and sham-treated (Figure 8E) mice to the ones of WT and Rd10 mice. In WT mice, the probability density function was broadly centered at $50 \mu \mathrm{V}$. All of the treated groups had a distribution that appeared to be concentrated around $50 \mu \mathrm{V}$ and narrower than the one of WT mice. In contrast, sham-treated and control groups distributions are skewed toward 0 , highlighting the higher amount of non-responding mice.

\section{DISCUSSION}

The eye is considered to be a preferential target for the delivery of gene therapies due to its accessibility and immune privilege (Sahel and Roska, 2012). Gene defects affecting photoreceptors cause the vast majority of IRDs; therefore, the development of neuroprotective, gene supplementation, and gene editing therapies has focused primarily on gene transfer to photoreceptors (Smith et al., 2012; Lipinski et al., 2015; Yu et al., 2017). While several retinal cell types can be successfully targeted by different viruses (Colella et al., 2009), the posterior segment of the eye, especially the photoreceptors, can be efficiently transduced only by adeno associated viruses (AAVs) (Allocca et al., 2007). Unfortunately, the maximum cargo capacity of these vectors is around $4.7 \mathrm{~kb}$, making them not suitable for the delivery of large genes. CRISPR/Cas9 plasmids are usually bigger than $5 \mathrm{~kb}$ and do not fit into AAVs. Hence, to deliver this gene editing tools, it is necessary to either combine more than one AAV vector (Trapani et al., 2014; Trapani, 2017) or use other less safe viral vectors with larger cargo capacity (Rossidis et al., 2018). A smaller Cas9 variant, delivered using AAVs, was recently used to disrupt and thus inactivate the $\mathrm{P} 23 \mathrm{H}$ mutated allele in a mouse model of dominant retinitis pigmentosa, but the authors reported a poor cleavage efficiency (Giannelli et al., 2018). Moreover, even though viruses represent the gold standard for gene delivery to the eye, their use does not cease to raise concerns about immunogenicity, long-term safety, and limited possibility 


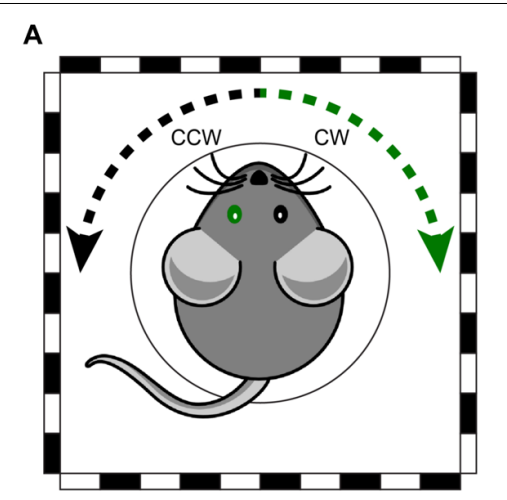

D

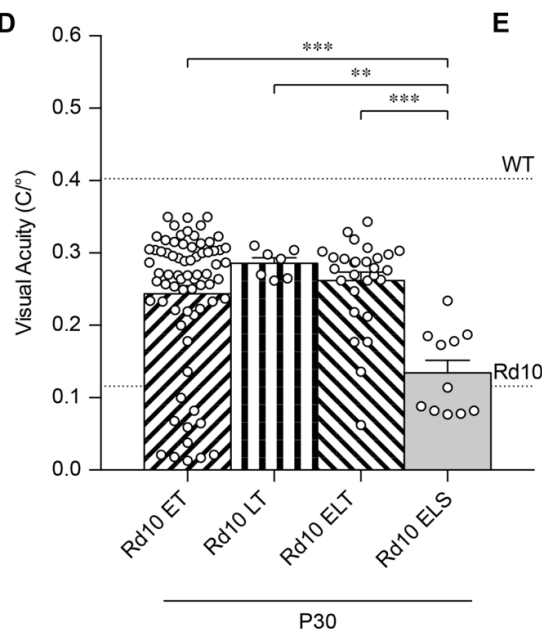

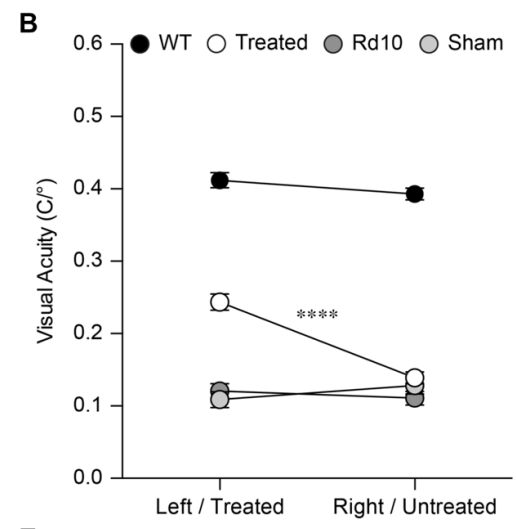

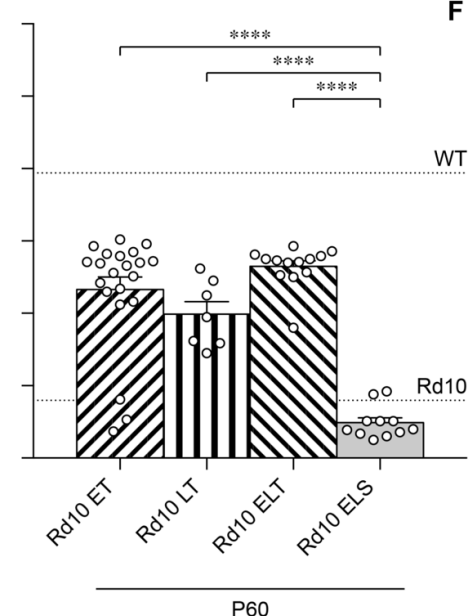

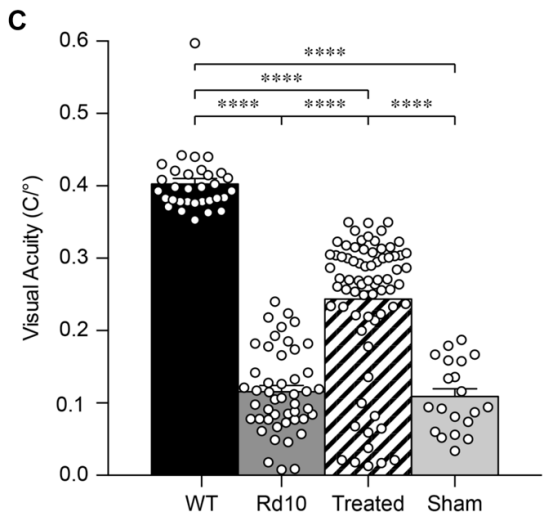

F

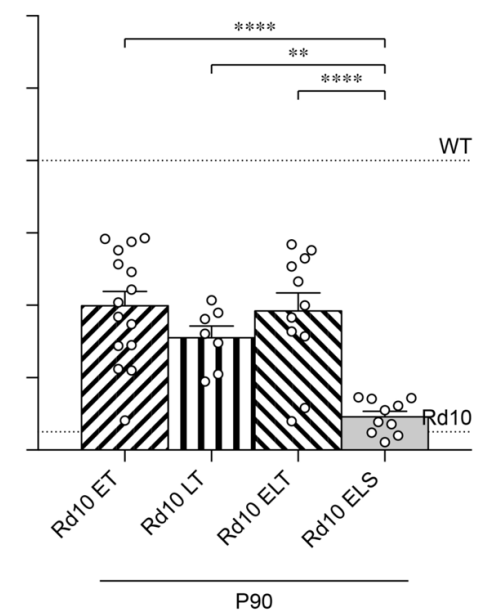

FIGURE 5 | Preservation of the visual acuity in Rd10 treated mice. (A) For each mouse, both the clock-wise (CW, left eye) and counter clock-wise (CCW, right eye) responses were assessed. The sketch represents a mouse with treatment (green) in the left eye (corresponding to the CW response). (B) Mean ( \pm SEM) visual acuity in WT mice (black circles), untreated Rd10 mice (dark gray circles), Rd10 treated mice (white circles), and Rd10 sham-treated mice (light gray circles). (C) Statistical comparison among the 4 groups ( $p<0.0001$, One Way ANOVA): WT $\left(0.40 \pm 0.01 \mathrm{C} /{ }^{\circ}, n=32\right.$, averaged left and right responses), Rd10 $\left(0.12 \pm 0.01 \mathrm{C} /{ }^{\circ}, n=47\right.$, averaged left and right responses), Rd10 treated $\left(0.24 \pm 0.01 \mathrm{C} /{ }^{\circ}, n=71\right)$, and Rd10 sham $\left(0.11 \pm 0.01 \mathrm{C} /{ }^{\circ}, n=20\right)$. (D) Statistical comparison $(p<0.001,0$. Way ANOVA) of the mean ( \pm SEM) visual acuity among Rd10 ET $\left(0.24 \pm 0.01 \mathrm{C} /{ }^{\circ}, n=71\right), \operatorname{Rd} 10 \mathrm{LT}\left(0.29 \pm 0.01 \mathrm{C} /{ }^{\circ}, n=7\right), \mathrm{Rd} 10 \mathrm{ELT}\left(0.26 \pm 0.01 \mathrm{C} /{ }^{\circ}, n=28\right)$, and Rd10 ELS $\left(0.13 \pm 0.02 \mathrm{C} /{ }^{\circ}, \mathrm{n}=11\right)$ at P30. (E) Statistical comparison $(p<0.0001$, One Way ANOVA) of the mean $( \pm S E M)$ visual acuity among Rd10 ET $\left(0.23 \pm 0.02 \mathrm{C}^{\circ}, n=21\right)$, Rd10 LT $\left(0.20 \pm 0.02 \mathrm{C} /{ }^{\circ}, n=7\right)$, Rd10 ELT (0.26 $\left.\pm 0.01 \mathrm{C} /{ }^{\circ}, n=13\right)$, and Rd10 ELS (0.05 $\left.\pm 0.02 \mathrm{C} /{ }^{\circ}, n=11\right)$ at P60. (F) Statistical comparison ( $p<0.0001$, One Way ANOVA) of the mean ( \pm SEM) visual acuity among Rd10 ET $\left(0.20 \pm 0.02 \mathrm{C} /{ }^{\circ}, n=15\right), \mathrm{Rd} 10 \mathrm{LT}\left(0.15 \pm 0.02 \mathrm{C} /{ }^{\circ}, n=7\right), \mathrm{Rd} 10$ $\operatorname{ELT}\left(0.20 \pm 0.03 \mathrm{C} /{ }^{\circ}, n=11\right)$, and Rd10 ELS $\left(0.05 \pm 0.02 \mathrm{C} /{ }^{\circ}, n=10\right)$ at P90. In $(\mathbf{C}-\mathbf{F})$, each circle represents a single mouse.

for repeated administration (Thomas et al., 2003; Baum et al., 2006; Yoshioka et al., 2006; Worgall et al., 2008). Conversely, non-viral gene delivery strategies (Niidome and Huang, 2002; Al-Dosari and Gao, 2009) permit the multiple administration of large therapeutic agents using less immunogenic and toxic plasmid vectors, but the resulting gene expression is often short-lived (Bainbridge et al., 2006; Andrieu-Soler et al., 2007; Han et al., 2011). This is usually an unappealing characteristic for a clinical application, but it does not represent a concern when editing tools need to be active only for a short period required to correct the sequence of the gene of interest. Among the non-viral delivery strategies, electroporation is one of the most efficient for the introduction of DNA into cells and holds a promising therapeutic potential (Dal Maschio et al., 2012; Cancedda et al., 2013; Szczurkowska et al., 2013, 2016; Cwetsch et al., 2018).
In fact, electroporation has been exploited for introducing genetic material and drugs in different tissues and organs and for the treatment of cancer (Gothelf et al., 2003; Lambricht et al., 2015; Cwetsch et al., 2018). According to in vitro reports (Hornstein et al., 2016), the size of the plasmid does not have any impact on the transfection efficiency, making the technique suitable for the delivery of large genes that would not fit into AAV viruses. Electroporation has been widely used to study the mouse retina development (Matsuda and Cepko, 2004, 2007, 2008) but is still under investigation for therapeutic purposes. The only reported use of electroporation on the human eye is in the human ciliary muscle (Touchard et al., 2009). Albeit it has not yet been applied to the human retina, it has been shown to successfully target different retinal cell types, both in young (Matsuda and Cepko, 2007; Wang et al., 2014) and adult (Touchard et al., 2012) mice. 


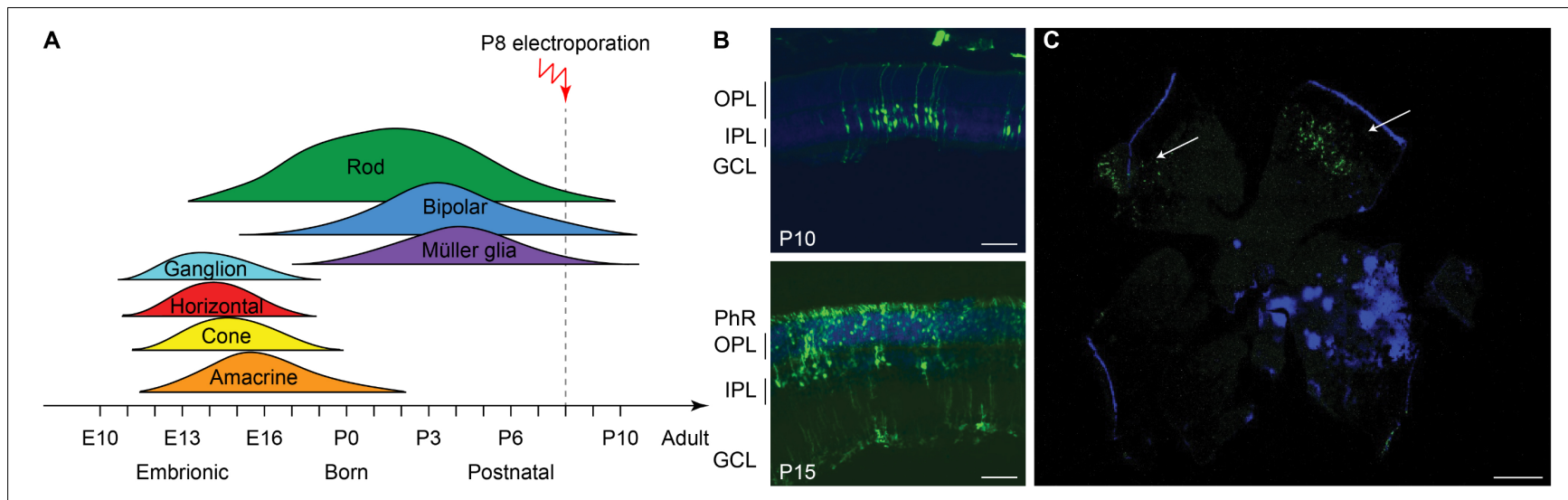

FIGURE 6 | Electroporation in vivo of photoreceptor progenitor cells at P8. (A) Sketch of the late electroporation time point (P8), at the end of the proliferation period. (B) Retinal sections from mice electroporated at P8. The sections were collected at two time points after electroporation: P10 and P15. The scale bar is $60 \mu \mathrm{m}$. On the side, the $\mathrm{PhR}$, the $\mathrm{OPL}$, the $\mathrm{PL}$, and the GCL are reported. (C) Wholemount retina electroporated at P8 and collected at P15, illustrating the spread of the electroporation (white arrows). The scale bar is $500 \mu \mathrm{m}$.
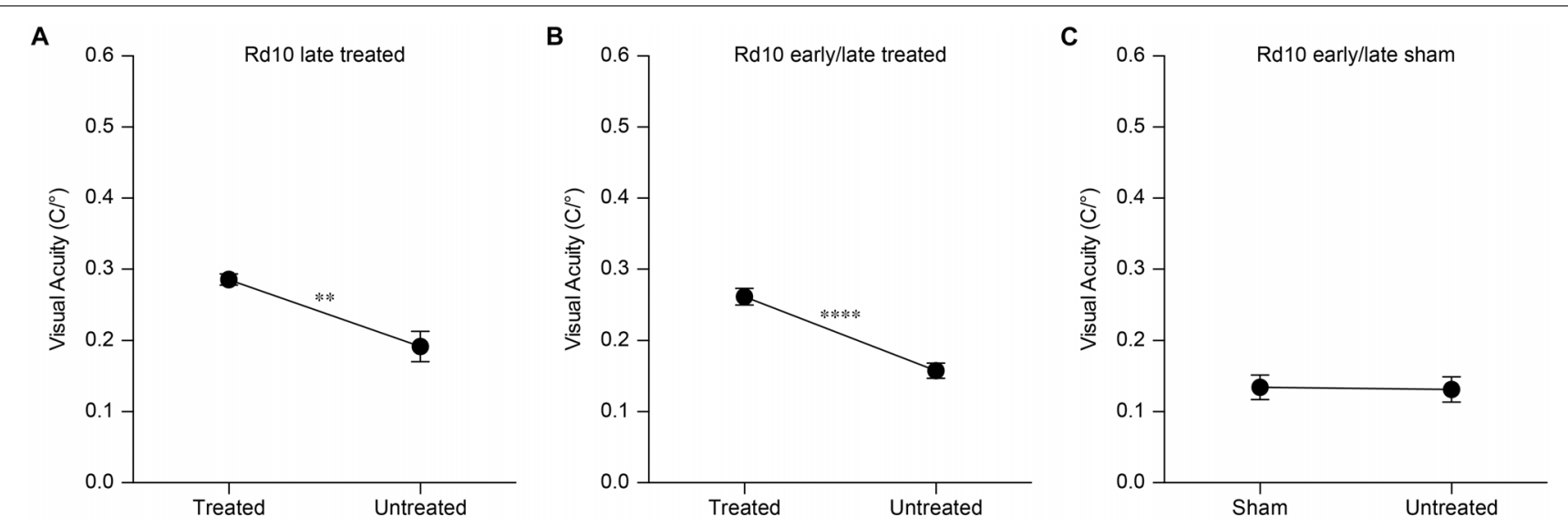

FIGURE 7 | Optomotor reflex upon electroporation at P8. (A) Mean ( \pm SEM) visual acuity in Rd10 mice treated at P8 (Rd10 LT; treated eye $0.29 \pm 0.01 \mathrm{C} /{ }^{\circ}$, untreated eye $0.19 \pm 0.02 \mathrm{C} /{ }^{\circ} ; n=7, p<0.01$, unpaired $t$-test). (B) Mean ( \pm SEM) visual acuity in Rd10 mice treated at P3 and P8 (Rd10 ELT; treated eye $0.26 \pm 0.01 \mathrm{C} /{ }^{\circ}$, untreated eye $0.16 \pm 0.01 \mathrm{C} /{ }^{\circ} ; n=28, p<0.0001$, unpaired $t$-test). (C) Mean ( \pm SEM) visual acuity in Rd10 mice sham treated at P3 and P8 (Rd10 ELS; sham eye $0.13 \pm 0.02 \mathrm{C} /{ }^{\circ}$, untreated eye $0.13 \pm 0.02 \mathrm{C} /{ }^{\circ} ; n=11, p=0.8992$, unpaired $t$-test).

In our opinion, electroporation is an attractive alternative method for the delivery of large therapeutic plasmids in the eye. Indeed, CRISPR/Cas9 constructs were also successfully delivered by electroporation in photoreceptor cells to target and disrupt by NHEJ the rhodopsin mutated allele in heterozygous $\mathrm{P} 23 \mathrm{H}$ mice (Latella et al., 2016; Giannelli et al., 2018) and in S334ter rats, both model of autosomal dominant retinitis pigmentosa (Bakondi et al., 2016). Nevertheless, loss of function mutations (like the one affecting Rd10 mice) are more difficult to address since the faulty sequence has to be actively edited by HDR to restore the correct gene product and not just disrupted as in the examples cited above.

In this work, retinal electroporation was exploited to deliver a therapeutic DNA mixture to photoreceptor cells. We treated Rd10 mice during photoreceptor development using a CRISPR/Cas9-based gene editing strategy to prevent retinal degeneration and observed preservation of visual functions in vitro and in vivo, in both subcortical visual-driven behavioral responses (optomotor reflex) and cortical visual responses (VEP) until as late as P90. However, the visual acuity, measured with the optomotor test, eventually declined at the P90, even in treated mice. We hypothesize that, since the coverage of the injection is not enough to edit the DNA of all the photoreceptor cells, eventually, also the edited cells succumb to the adverse effect of pro-apoptotic factors released by the non-edited dying cells. Multiple cycles of injections followed by electroporation could solve this issue by allowing the gene editing of a higher number of photoreceptors, especially if performed during the progenitor proliferation period. Notably, we have demonstrated that a repeated treatment (at P3 and P8) is not detrimental for the mice. However, the mouse, especially the pup, is not an ideal model to test this hypothesis, given the tiny size of the eyes: multiple injections and electroporation would damage the eye excessively. Similarly, early 
A

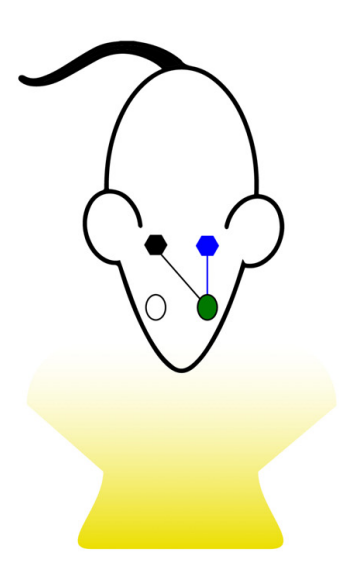

WT<smiles>[R2]OCC</smiles>

D

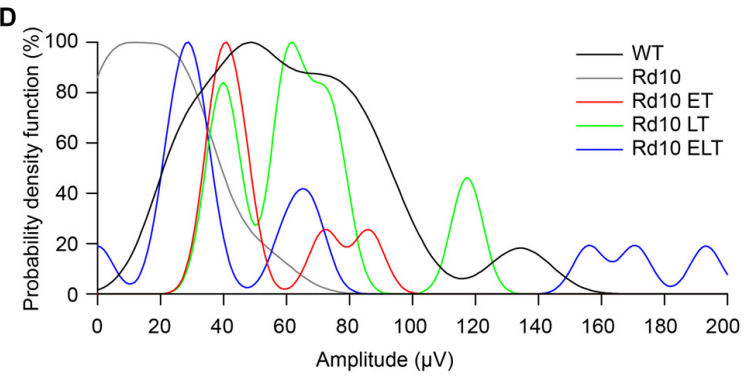

B

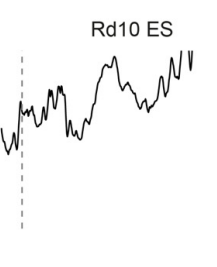

Rd10 ELS

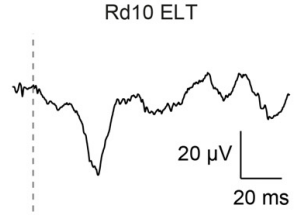

Rd10 LT
Rd10 ET

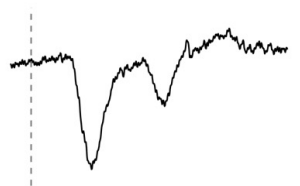

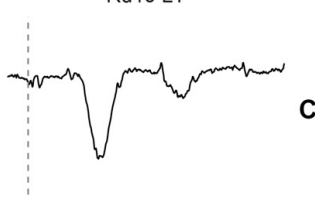

$$
\text { C }
$$
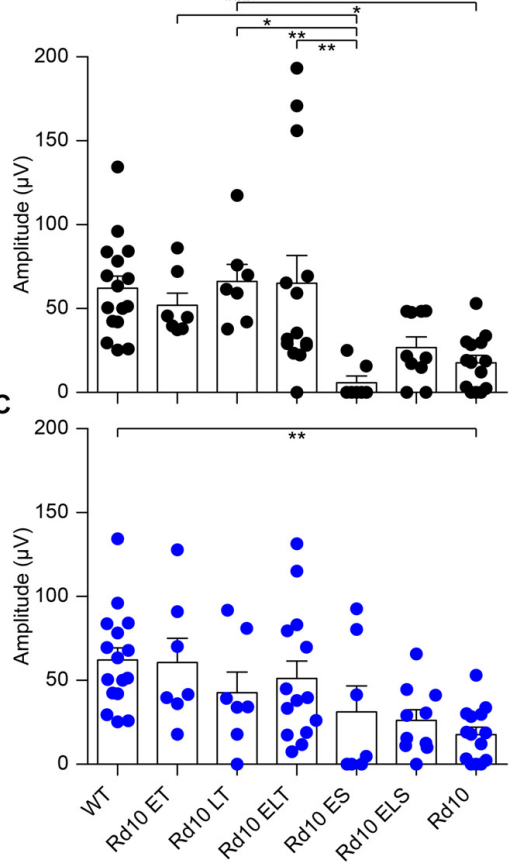

E

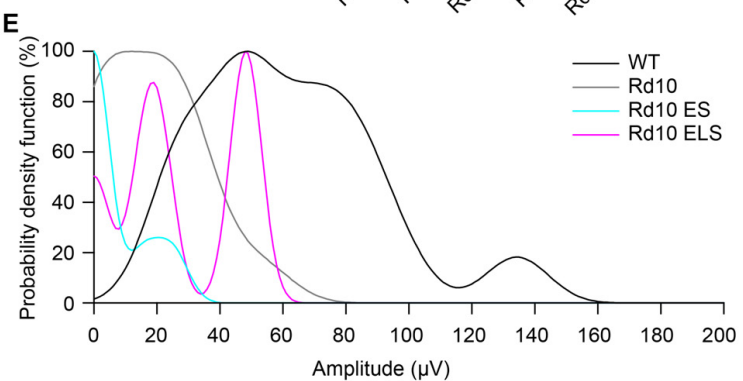

FIGURE 8 | Preservation of visually evoked potentials at P90. (A) Sketch of the recording setup in which the cortex contralateral to the treated eye (green) is in black, while the ipsilateral is in blue. Representative VEP response for each experimental group. The gray dashed lines are the occurrence of the flash. For treated (Rd10 ET, Rd10 LT, and Rd10 ELT) and sham-treated (Rd10 ES and Rd10 ELS) mice, the traces are from the contralateral cortex, while for WT and Rd10 mice the responses of the two cortices were averaged. (B) Mean ( \pm SEM) contralateral peak amplitude for all the experimental groups: WT (91.7 $\pm 11.1 \mu \mathrm{V}, n=16), \mathrm{Rd} 10 \mathrm{ET}$ (62.4 $\pm 9.4 \mu \mathrm{V}, n=7), \operatorname{Rd10} \mathrm{LT}(73.1 \pm 10.8 \mu \mathrm{V}, n=7)$, Rd10 ELT (71.7 $\pm 15.2 \mu \mathrm{V}, n=14), \operatorname{Rd} 10 \mathrm{ES}(13.7 \pm 8.9 \mu \mathrm{V}, n=7), \mathrm{Rd} 10 \mathrm{ELS}(34.4 \pm 7.1 \mu \mathrm{V}, n=10)$, and $\operatorname{Rd10}(23.8 \pm 5.5 \mu \mathrm{V}, n=14)$. (C) Mean ( \pm SEM) ipsilateral peak amplitude for all the experimental groups: WT (91.7 $\pm 11.1 \mu \mathrm{V}, n=16), \mathrm{Rd} 10 \mathrm{ET}(69.6 \pm 14.4 \mu \mathrm{V}$ $n=7), \operatorname{Rd} 10 \mathrm{LT}(49.8 \pm 12.8 \mu \mathrm{V}, n=7), \operatorname{Rd} 10 \mathrm{ELT}(96.6 \pm 20.7 \mu \mathrm{V}, n=14), \operatorname{Rd} 10 \mathrm{ES}(48.0 \pm 21.9 \mu \mathrm{V}, n=7), \operatorname{Rd} 10 \mathrm{ELS}(30.8 \pm 7.0 \mu \mathrm{V}, n=10)$, and Rd10 $(23.8 \pm 5.5 \mu \mathrm{V}, n=14)$. In (B,C), for WT and Rd10 mice the responses of the two cortices were averaged before computing the peak amplitude; therefore, they are equal. (D) Probability density functions fitted using a Kernel distribution of the contralateral response for the treated groups (Rd10 ET, Rd10 LT, and Rd10 ELT) compared to WT and Rd10 mice. (E) Probability density functions fitted with a Kernel distribution of the contralateral response for the sham-treated groups (Rd10 ES and Rd10 ELS) mice compared to WT and Rd10 mice.

intervention on new-born pups (P0-P1) could result in higher editing efficiency.

P3 and, even more so, P8 are considered late timepoints for an intervention in mice (Bakondi et al., 2016; Latella et al., 2016), since P3 is at the beginning of the descending curve of rod proliferation and P8 is at its very end (Zhang et al., 2011). However, it is currently not possible to translate this approach to human patients given that the available screening methods allow the detection of retinal degeneration only at a late stage and our therapeutic tool is relying on the HDR mechanism, which is much less active in post-mitotic cells. Nevertheless, some future improvement might change this situation. For instance, although we used a standard CRISPRCas9 construct, various research groups are working on ways to improve the efficiency of HDR in post-mitotic cells. This has been successfully achieved in different ways: for instance, using molecules that are inhibiting NHEJ (Chu et al., 2015), exerting temporal control on Cas9 expression (Lin et al., 2014), and covalently tethering the repair template to the Cas9 protein to increase its concentration on the site of the DNA doublestrand break (Aird et al., 2018). Moreover, in the future, more advanced diagnostic tools might be available to enable an early detection of the degeneration, prior to the onset of the symptoms. 

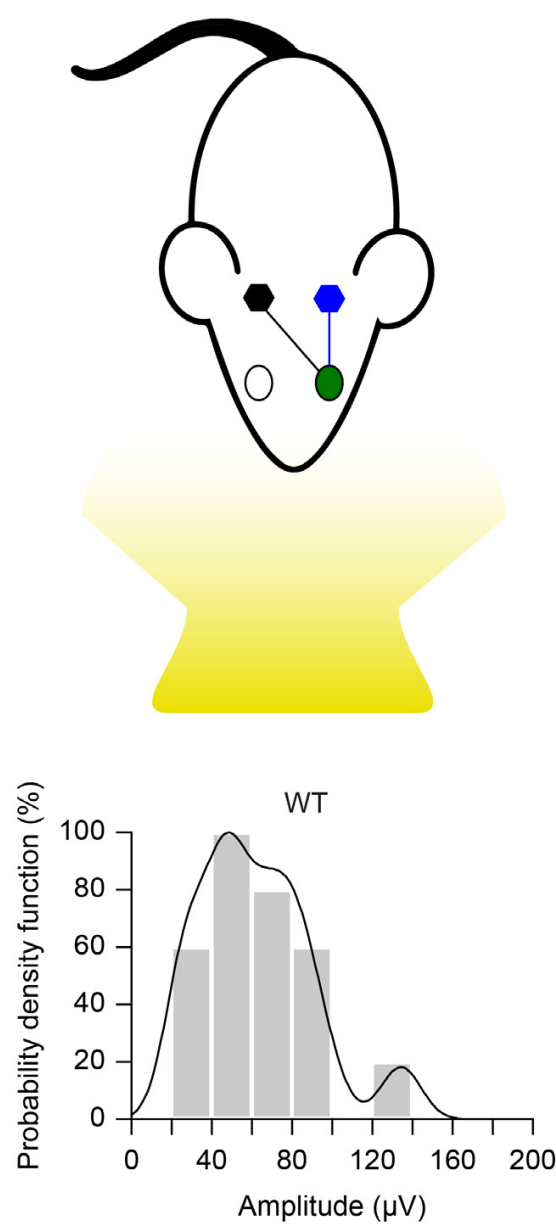

$\operatorname{Rd} 10$

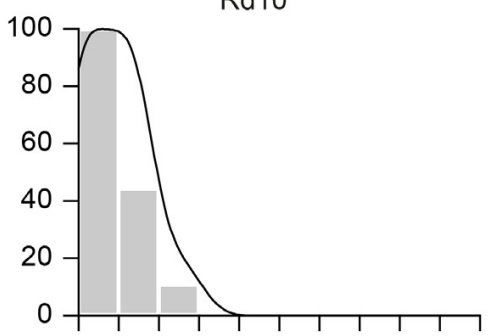

Rd10 ES

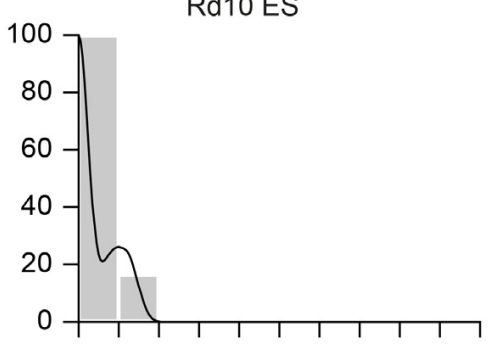

Rd10 ELS

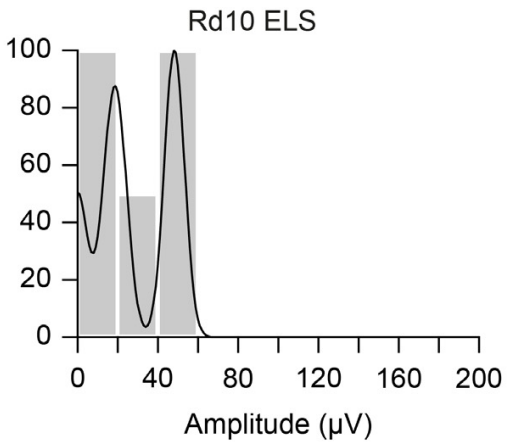

Rd10 ET

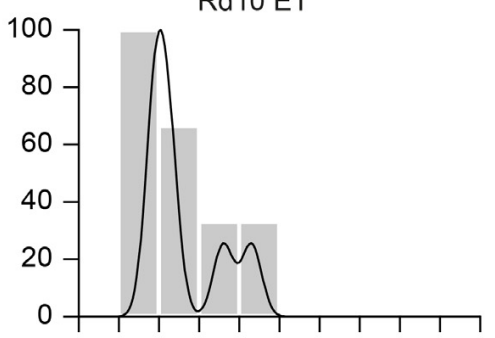

Rd10 LT

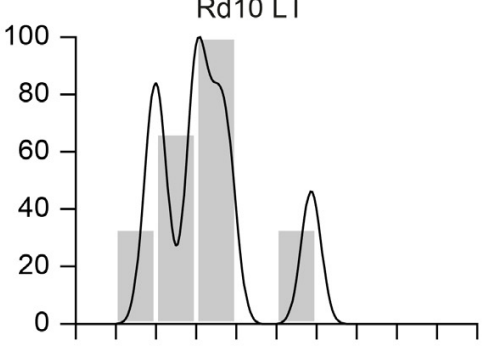

Rd10 ELT

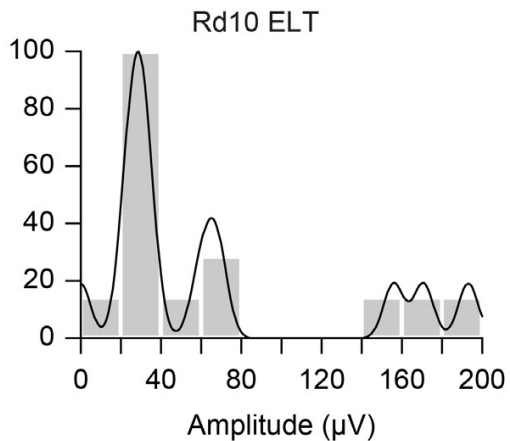

FIGURE 9 | Probability density function. Each panel shows the histogram (20 $\mu \mathrm{V}$ bins) of the VEP peak amplitude and the fitted Kernel distribution for all the experimental groups. For treated (Rd10 ET, Rd10 LT, and Rd10 ELT) and sham treated (Rd10 ES and Rd10 ELS) mice, the data are from recordings in the cortex (black) contralateral to the treated eye (green).

\section{CONCLUSION}

In conclusion, we provide an example of how CRISPR/Cas9 gene editing can be coupled with electroporation for therapeutic purpose, along with a discussion of the limitations that need to be overcome to translate this approach to the clinics. Issues related to safety of retinal electroporation in large animals, repeatability of the treatment, transfection efficiency, retinal coverage, gene expression levels, and disease stage at the age of injection still need a careful investigation to improve the therapeutic benefits of CRISPR/Cas9-based gene editing strategies. On the other hand, the ease of design of the CRISPR/Cas9 gene editing systems makes them easily tailorable for several mutations in perspective of a patient-specific therapy. This concept applies particularly when there are small differences in the DNA sequence, as in the case of autosomal recessive mutations. Our non-viral delivery approach has two main advantages compared to previous reports in small animal models in which retinal degeneration was prevented by viral-mediated delivery of Cas9. First, in perspective of a possible clinical application, it circumvents possible safety issues deriving from viral-based gene therapy. Secondly, plasmid vector delivery by electroporation will result in transient expression of Cas9, therefore limiting the possible occurrence of off-target activity of the nuclease after longterm expression.

\section{DATA AVAILABILITY}

The authors declare that all other relevant data supporting the findings of the study are available in this article. Access to our raw data can be obtained from the corresponding author upon reasonable request.

\section{ETHICS STATEMENT}

Animal experiments were performed according to the animal authorizations VD3044 issued by the Service de 
la Consommation et des Affaires Vétérinaires (SCAV) of the Canton de Vaud (Switzerland), GE3217 issued by the Département de l'Emploi, des Affaires sociales et de la Santé (DEAS), Direction Générale de la Santé of the Republique et Canton de Genève (Switzerland), and 726/2015-PR issued by the Italian Ministry of Health.

\section{AUTHOR CONTRIBUTIONS}

PV performed all the experiments and wrote the manuscript. LP designed the gene editing strategy, generated the plasmids, and performed the in vitro validation of the plasmids. NC performed the experiments with explanted retinas. TM contributed to the in vivo electrophysiology. MP contributed to the setting of pilot behavioral experiments. AC designed the study, designed the gene editing and screening strategies, performed the ddPCR, and wrote the manuscript. LC designed the study. DG designed the study, led the whole project, and wrote the manuscript. All the authors read, edited, and accepted the manuscript.

\section{REFERENCES}

Aird, E. J., Lovendahl, K. N., St. Martin, A., Harris, R. S., and Gordon, W. R. (2018). Increasing Cas9-mediated homology-directed repair efficiency through covalent tethering of DNA repair template. Commun. Biol. 1:54. doi: 10.1038/ s42003-018-0054-2

Al-Dosari, M. S., and Gao, X. (2009). Nonviral gene delivery: principle, limitations, and recent progress. AAPS J. 11, 671-681. doi: 10.1208/s12248-009-9143-y

Allocca, M., Mussolino, C., Garcia-Hoyos, M., Sanges, D., Iodice, C., Petrillo, M., et al. (2007). Novel adeno-associated virus serotypes efficiently transduce murine photoreceptors? J. Virol. 81, 11372-11380. doi: 10.1128/jvi.01 327-7

Andrieu-Soler, C., Halhal, M., Boatright, J. H., Padove, S. A., Nickerson, J. M., Stodulkova, E., et al. (2007). Single-stranded oligonucleotide-mediated in vivo gene repair in the rd1 retina. Mol. Vis. 13, 692-706.

Auricchio, A., Smith, A. J., and Ali, R. R. (2017). The future looks brighter after 25 years of retinal gene therapy. Hum. Gene Ther. 28, 982-987. doi: 10.1089/hum. 2017.164

Bainbridge, J. W. B., Tan, M. H., and Ali, R. R. (2006). Gene therapy progress and prospects: the eye. Gene Ther. 13:3302812. doi: 10.1038/sj.gt.3302812

Bakondi, B., Lv, W., Lu, B., Jones, M. K., Tsai, Y., Kim, K. J., et al. (2016). In Vivo CRISPR/Cas9 gene editing corrects retinal dystrophy in the S334ter-3 rat model of autosomal dominant retinitis pigmentosa. Mol. Ther. 24, 556-563. doi: $10.1038 / \mathrm{mt} .2015 .220$

Baum, C., Kustikova, O., Modlich, U., Li, Z., and Fehse, B. (2006). Mutagenesis and oncogenesis by chromosomal insertion of gene transfer vectors. Hum. Gene Ther. 17, 253-263. doi: 10.1089/hum.2006.17.253

Bennett, J., Tanabe, T., Sun, D., Zeng, Y., Kjeldbye, H., Gouras, P., et al. (1996). Photoreceptor cell rescue in retinal degeneration ( $\mathrm{rd}$ ) mice by in vivo gene therapy. Nat. Med. 2, 649-654. doi: 10.1038/nm0696-649

Bureau, M. F., Gehl, J., Deleuze, V., Mir, L. M., and Scherman, D. (2000). Importance of association between permeabilization and electrophoretic forces for intramuscular DNA electrotransfer. Biochim. Biophys. Acta Gen. Subj. 1474, 353-359. doi: 10.1016/s0304-4165(00)00028-3

Cancedda, L., Szczurkowska, J., Cwetsch, A. W., Dal Maschio, M., Ghezzi, D., Ratto, G. M., et al. (2013). High-performance and reliable sitedirected in vivo genetic manipulation of mouse and rat brain by in utero electroporation with a triple-electrode probe. Protoc. Exch. doi: 10.1038/protex. 2013.089

Chang, B., Hawes, N. L., Hurd, R. E., Davisson, M. T., Nusinowitz, S., and Heckenlively, J. R. (2002). Retinal degeneration mutants in the mouse. Vision Res. 42, 517-525. doi: 10.1016/s0042-6989(01)00146-8

\section{FUNDING}

This work was supported by the École polytechnique fédérale de Lausanne, Medtronic, 2014 Global Ophthalmology Awards Program (GOAP) by Bayer HealthCare to DG, Compagnia di San Paolo (Italy) grant 9734 to AC, and the European Research Council (ERC) under the European Union's Horizon 2020 Research and Innovation Program (Grant Agreement No. 725563$)$ to LC.

\section{ACKNOWLEDGMENTS}

We thank Elodie Meyer at the Medtronic Chair in Neuroengineering for her help with retinal histology, Aurelién Lacombe at the Wyss Center for Bio and Neuroengineering for his support on molecular biology, Ennio Albanesi at the Istituto Italiano di Tecnologia for FACS isolation of cells, and Dr. Sui Wang and Prof. Constance Cepko at the Harvard Medical School for their help with subretinal electroporation.

Chang, B., Hawes, N. L., Pardue, M. T., German, A. M., Hurd, R. E., Davisson, M. T., et al. (2007). Two mouse retinal degenerations caused by missense mutations in the $\beta$-subunit of rod cGMP phosphodiesterase gene. Vision Res. 47, 624-633. doi: 10.1016/j.visres.2006.11.020

Chu, V. T., Weber, T., Wefers, B., Wurst, W., Sander, S., Rajewsky, K., et al. (2015). Increasing the efficiency of homology-directed repair for CRISPR-Cas9induced precise gene editing in mammalian cells. Nat. Biotechnol. 33, 543-548. doi: 10.1038/nbt.3198

Colella, P., Cotugno, G., and Auricchio, A. (2009). Ocular gene therapy: current progress and future prospects. Trends Mol. Med. 15, 23-31. doi: 10.1016/j. molmed.2008.11.003

Coleman, J. E., Law, K., and Bear, M. F. (2009). Anatomical origins of ocular dominance in mouse primary visual cortex. Neuroscience 161, 561-571. doi: 10.1016/j.neuroscience.2009.03.045

Cong, L., Ran, A. F., Cox, D., Lin, S., Barretto, R., Habib, N., et al. (2013). Multiplex genome engineering using CRISPR/Cas systems. Science 339, 819-823. doi: 10.1126/science. 1231143

Cwetsch, A. W., Pinto, B., Savardi, A., and Cancedda, L. (2018). In vivo methods for acute modulation of gene expression in the central nervous system. Prog. Neurobiol. 168, 69-85. doi: 10.1016/j.pneurobio.2018.04.008

Dal Maschio, M., Ghezzi, D., Bony, G., Alabastri, A., Deidda, G., Brondi, M., et al. (2012). High-performance and site-directed in utero electroporation by a triple-electrode probe. Nat. Commun. 3:960. doi: 10.1038/ncomms1961

Danciger, M., Blaney, J., Gao, Y. Q., Zhao, D. Y., Heckenlively, J. R., Jacobson, S. G., et al. (1995). Mutations in the PDE6B gene in autosomal recessive retinitis pigmentosa. Genomics 30, 1-7. doi: 10.1006/geno.1995.0001

de Melo, J., and Blackshaw, S. (2011). In vivo electroporation of developing mouse retina. J Vis Exp. 24:2847. doi: 10.3791/2847

Douglas, R. M., Alam, N. M., Silver, B. D., Mcgill, T. J., Tschetter, W. W., and Prusky, G. T. (2005). Independent visual threshold measurements in the two eyes of freely moving rats and mice using a virtual-reality optokinetic system. Vis. Neurosci. 22, 677-684. doi: 10.1017/S0952523805225166

Ferrari, S., Iorio, E. D., Barbaro, V., Ponzin, D., Sorrentino, F. S., and Parmeggiani, F. (2011). Retinitis pigmentosa: genes and disease mechanisms. Curr. Genomics 12, 238-249. doi: 10.2174/138920211795860107

Gargini, C., Terzibasi, E., Mazzoni, F., and Strettoi, E. (2007). Retinal organization in the retinal degeneration 10 (rd10) mutant mouse: a morphological and ERG study. J. Comp. Neurol. 500, 222-238. doi: 10.1002/cne.21144

Giannelli, S. G., Luoni, M., Castoldi, V., Massimino, L., Cabassi, T., Angeloni, D., et al. (2018). Cas9/sgRNA selective targeting of the P23H Rhodopsin mutant allele for treating retinitis pigmentosa by intravitreal AAV9.PHP.Bbased delivery. Hum. Mol. Genet. 27, 761-779. doi: 10.1093/hmg/ddx438 
Gothelf, A., Mir, L. M., and Gehl, J. (2003). Electrochemotherapy: results of cancer treatment using enhanced delivery of bleomycin by electroporation. Cancer Treat. Rev. 29, 371-387. doi: 10.1016/s0305-7372(03)00073-2

Han, Z., Conley, S. M., and Naash, M. I. (2011). AAV and compacted DNA nanoparticles for the treatment of retinal disorders: challenges and future prospects. Invest. Ophthalmol. Vis. Sci. 52, 3051-3059. doi: 10.1167/iovs.106916

Harvey, R. J., De'sperati, C., and Strata, P. (1997). The early phase of horizontal optokinetic responses in the pigmented rat and the effects of lesions of the visual cortex. Vision Res. 37, 1615-1625. doi: 10.1016/S0042-6989(96)00292-1

Heidenreich, M., and Zhang, F. (2016). Applications of CRISPR-Cas systems in neuroscience. Nat. Rev. Neurosci. 17, 36-44. doi: 10.1038/nrn.2015.2

Hobbelen, J. F., and Collewijn, H. (1971). Effect of cerebro-cortical and collicular ablations upon the optokinetic reactions in the rabbit. Doc. Ophthalmol. 30, 227-236. doi: 10.1007/bf00142521

Hornstein, B. D., Roman, D., Arévalo-Soliz, L. M., Engevik, M. A., and Zechiedrich, L. (2016). Effects of circular DNA length on transfection efficiency by electroporation into HeLa cells. PLoS One 11:e0167537. doi: 10.1371/journal. pone. 0167537

Jae, S. A., Ahn, K. N., Kim, J. Y., Seo, J. H., Kim, H. K., and Goo, Y. S. (2013). Electrophysiological and histologic evaluation of the time course of retinal degeneration in the rd10 mouse model of retinitis pigmentosa. Korean J. Physiol. Pharmacol. 17, 229-235. doi: 10.4196/kjpp.2013.17.3.229

Jomary, C., Vincent, K., Grist, J., Neal, M., and Jones, S. (1997). Rescue of photoreceptor function by AAV-mediated gene transfer in a mouse model of inherited retinal degeneration. Gene Ther. 4:3300440. doi: 10.1038/sj.gt. 3300440

Lambricht, L., Lopes, A., Kos, S., Sersa, G., Préat, V., and Vandermeulen, G. (2015). Clinical potential of electroporation for gene therapy and DNA vaccine delivery. Expert Opin. Drug Deliv. 13, 295-310. doi: 10.1517/17425247.2016.1121990

Latella, M. C., Salvo, M. T. D., Cocchiarella, F., Benati, D., Grisendi, G., Comitato, A., et al. (2016). In vivo editing of the human mutant rhodopsin gene by electroporation of plasmid-based CRISPR/Cas9 in the mouse retina. Mol. Ther. Nucleic Acids 5:e389. doi: 10.1038/mtna.2016.92

Lin, S., Staahl, B. T., Alla, R. K., and Doudna, J. A. (2014). Enhanced homologydirected human genome engineering by controlled timing of CRISPR/Cas9 delivery. eLife 3:e04766. doi: 10.7554/eLife.04766

Lipinski, D. M., Barnard, A. R., Singh, M. S., Martin, C., Lee, E. J., Davies, W. I. L., et al. (2015). CNTF gene therapy confers lifelong neuroprotection in a mouse model of human retinitis pigmentosa. Mol. Ther. 23, 1308-1319. doi: 10.1038/ mt.2015.68

MacLaren, R., Pearson, R., MacNeil, A., Douglas, R., Salt, T., Akimoto, M., et al. (2006). Retinal repair by transplantation of photoreceptor precursors. Nature 444, 203-207. doi: 10.1038/nature05161

Matsuda, T., and Cepko, C. L. (2004). Electroporation and RNA interference in the rodent retina in vivo and in vitro. Proc. Natl. Acad. Sci. U.S.A. 101, 16-22. doi: $10.1073 /$ pnas. 2235688100

Matsuda, T., and Cepko, C. L. (2007). Controlled expression of transgenes introduced by in vivo electroporation. Proc. Natl. Acad. Sci. U.S.A. 104, 10271032. doi: 10.1073/pnas.0610155104

Matsuda, T., and Cepko, C. L. (2008). Analysis of gene function in the retina. Methods Mol. Biol. 423, 259-278. doi: 10.1007/978-1-59745-194-9_19

McLaughlin, M., Ehrhart, T., Berson, E., and Dryja, T. (1995). Mutation spectrum of the gene encoding the beta subunit of rod phosphodiesterase among patients with autosomal recessive retinitis pigmentosa. Proc. Natl. Acad. Sci. U.S.A. 92, 3249-3253. doi: 10.1073/pnas.92.8.3249

Mohand-Said, S., Hicks, D., Dreyfus, H., and Sahel, J. A. (2000). Selective transplantation of rods delays cone loss in a retinitis pigmentosa model. Arch. Ophthalmol. 118, 807-811. doi: 10.1001/archopht.118.6.807

Narayan, D. S., Wood, J. P. M., Chidlow, G., and Casson, R. J. (2016). A review of the mechanisms of cone degeneration in retinitis pigmentosa. Acta Ophthalmol. 94, 748-754. doi: 10.1111/aos.13141

Niidome, T., and Huang, L. (2002). Gene therapy progress and prospects: nonviral vectors. Gene Ther. 9, 1647-1652. doi: 10.1038/sj.gt.3301923

Pacey, L., Stead, S., Gleave, J., Tomczyk, K., and Doering, L. (2006). Neural stem cell culture: neurosphere generation, microscopical analysis and cryopreservation. Protoc. Exch. 10, 1-11. doi: 10.1038/nprot.2006.215
Pang, J., Boye, S. L., Kumar, A., Dinculescu, A., Deng, W., Li, J., et al. (2008). AAVmediated gene therapy for retinal degeneration in the $\mathrm{rd} 10$ mouse containing a recessive PDE $\beta$ mutation. Invest. Ophthalmol. Visual Sci. 49, 4278-4283. doi: 10.1167/iovs.07-1622

Pang, J.-J., Lei, L., Dai, X., Shi, W., Liu, X., Dinculescu, A., et al. (2012). AAVmediated gene therapy in mouse models of recessive retinal degeneration. Curr. Mol. Med. 12, 316-330. doi: 10.2174/156652412799218877

Pennesi, M. E., Michaels, K. V., Magee, S. S., Maricle, A., Davin, S. P., Garg, A. K., et al. (2012). Long-term characterization of retinal degeneration in $\mathrm{rd} 1$ and $\mathrm{rd} 10$ mice using spectral domain optical coherence tomography. Invest. Ophthalmol. Visual Sci. 53, 4644-4656. doi: 10.1167/iovs.12-9611

Pinto, L. H., Invergo, B., Shimomura, K., Takahashi, J. S., and Troy, J. B. (2007). Interpretation of the mouse electroretinogram. Doc. Ophthalmol. 115, 127-136. doi: 10.1007/s10633-007-9064-y

Prusky, G. T., Alam, N. M., Beekman, S., and Douglas, R. M. (2004). Rapid quantification of adult and developing mouse spatial vision using a virtual optomotor system. Invest. Ophthalmol. Visual Sci. 45, 4611-4616. doi: 10.1167/ iovs.04-541

Ran, A. F., Hsu, P. D., Wright, J., Agarwala, V., Scott, D. A., and Zhang, F. (2013). Genome engineering using the CRISPR-Cas9 system. Nat. Protoc. 8, 2281-2308. doi: 10.1038/nprot.2013.143

Rossidis, A. C., Stratigis, J. D., Chadwick, A. C., Hartman, H. A., Ahn, N. J., Li, H., et al. (2018). In utero CRISPR-mediated therapeutic editing of metabolic genes. Nat. Med. 24, 1513-1518. doi: 10.1038/s41591-018-0184-6

Sahel, J.-A., and Roska, B. (2012). Gene therapy for blindness. Annu. Rev. Neurosci. 36, 467-488. doi: 10.1146/annurev-neuro-062012-170304

Saleh-Gohari, N., and Helleday, T. (2004). Conservative homologous recombination preferentially repairs DNA double-strand breaks in the S phase of the cell cycle in human cells. Nucleic Acids Res. 32, 3683-3688. doi: 10.1093/nar/gkh703

Smith, A. J., Bainbridge, J. W., and Ali, R. R. (2012). Gene supplementation therapy for recessive forms of inherited retinal dystrophies. Gene Ther. 19, 154-161. doi: 10.1038/gt.2011.161

Stasheff, S. F., Shankar, M., and Andrews, M. P. (2011). Developmental time course distinguishes changes in spontaneous and light-evoked retinal ganglion cell activity in rd1 and rd10 mice. J. Neurophysiol. 105, 3002-3009. doi: 10.1152/ jn.00704.2010

Szczurkowska, J., Cwetsch, A. W., Dal Maschio, M., Ghezzi, D., Ratto, G., and Cancedda, L. (2016). Targeted in vivo genetic manipulation of the mouse or rat brain by in utero electroporation with a triple-electrode probe. Nat. Protoc. 11, 399-412. doi: 10.1038/nprot.2016.014

Szczurkowska, J., Dal Maschio, M., Cwetsch, A. W., Ghezzi, D., Bony, G., Alabastri, A., et al. (2013). "Increased performance in genetic manipulation by modeling the dielectric properties of the rodent brain," in Proceedings of the Annual International Conference of the IEEE Engineering in Medicine and Biology Society, Osaka, 1615-1618.

Thomas, B. B., Seiler, M. J., Sadda, S. R., Coffey, P. J., and Aramant, R. B. (2004). Optokinetic test to evaluate visual acuity of each eye independently. J. Neurosci. Methods 138, 7-13. doi: 10.1016/j.jneumeth.2004.03.007

Thomas, C. E., Ehrhardt, A., and Kay, M. A. (2003). Progress and problems with the use of viral vectors for gene therapy. Nat. Rev. Genet. 4, 346-358. doi: $10.1038 / \operatorname{nrg} 1066$

Touchard, E., Berdugo, M., Bigey, P., Sanharawi, M., Savoldelli, M., Naud, M.-C. C., et al. (2012). Suprachoroidal electrotransfer: a nonviral gene delivery method to transfect the choroid and the retina without detaching the retina. Mol. Ther. 20, 1559-1570. doi: 10.1038/mt.2011.304

Touchard, E., Bloquel, C., Bigey, P., Kowalczuk, L., Kowalczuc, L., Jonet, L., et al. (2009). Effects of ciliary muscle plasmid electrotransfer of TNF-alpha soluble receptor variants in experimental uveitis. Gene Ther. 16, 862-873. doi: 10.1038/ gt.2009.43

Trapani, I. (2017). Retinal gene therapy, methods and protocols. Methods Mol. Biol. 1715, 153-175. doi: 10.1007/978-1-4939-7522-8_11

Trapani, I., Colella, P., Sommella, A., Iodice, C., Cesi, G., Simone, S., et al. (2014). Effective delivery of large genes to the retina by dual AAV vectors. EMBO Mol. Med. 6, 194-211. doi: 10.1002/emmm.201302948

Tucker, B. A., Park, I.-H., Qi, S. D., Klassen, H. J., Jiang, C., Yao, J., et al. (2011). Transplantation of adult mouse iPS cell-derived photoreceptor precursors 
restores retinal structure and function in degenerative mice. PLoS One 6:e18992. doi: 10.1371/journal.pone.0018992

Ulshafer, R. J., Garcia, C. A., and Hollyfield, J. G. (1980). Sensitivity of photoreceptors to elevated levels of cGMP in the human retina. Invest. Ophthalmol. Visual Sci. 19, 1236-1241.

Wang, S., Sengel, C., Emerson, M. M., and Cepko, C. L. (2014). A gene regulatory network controls the binary fate decision of rod and bipolar cells in the vertebrate retina. Dev. Cell 30, 513-527. doi: 10.1016/j.devcel.2014. 07.018

Worgall, S., Sondhi, D., Hackett, N. R., Kosofsky, B., Kekatpure, M. V., Neyzi, N., et al. (2008). Treatment of late infantile neuronal ceroid lipofuscinosis by CNS administration of a Serotype 2 adeno-associated virus expressing CLN2 cDNA. Hum. Gene Ther. 19, 463-474. doi: 10.1089/hum. 2008.022

Yoshioka, Y., Abe, T., Wakusawa, R., Moriya, T., Mochizuki, S., Saigo, Y., et al. (2006). Recombinant AAV-transduced iris pigment epithelial cell transplantation may transfer vector to native RPE but suppress systemic dissemination. Invest. Ophthalmol. Visual Sci. 47, 745-752. doi: 10.1167/iovs. 05-398
Yu, W., Mookherjee, S., Chaitankar, V., Hiriyanna, S., Kim, J.-W., Brooks, M., et al. (2017). Nrl knockdown by AAV-delivered CRISPR/Cas9 prevents retinal degeneration in mice. Nat. Commun. 8:14716. doi: 10.1038/ncomms1 4716

Zhang, X., Serb, J. M., and Greenlee, M. H. W. (2011). Mouse retinal development: a dark horse model for systems biology research. Bioinform. Biol. Insights 5, 99-113. doi: 10.4137/bbi.s6930

Conflict of Interest Statement: The authors declare that the research was conducted in the absence of any commercial or financial relationships that could be construed as a potential conflict of interest.

Copyright (c) 2019 Vagni, Perlini, Chenais, Marchetti, Parrini, Contestabile, Cancedda and Ghezzi. This is an open-access article distributed under the terms of the Creative Commons Attribution License (CC BY). The use, distribution or reproduction in other forums is permitted, provided the original author(s) and the copyright owner(s) are credited and that the original publication in this journal is cited, in accordance with accepted academic practice. No use, distribution or reproduction is permitted which does not comply with these terms. 